\title{
Magnetic measurements with the FLASH infrared undulator
}

\author{
O. Grimm ${ }^{1}$, N. Morozov ${ }^{2}$, A. Chesnov ${ }^{2}$, Y. Holler ${ }^{3}$, E. Matushevsky ${ }^{2}$,

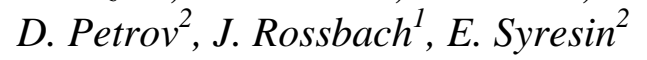 \\ ${ }^{1}$ University of Hamburg, Germany $\quad{ }^{2}$ JINR, Dubna, Russia $\quad{ }^{3}$ DESY, Hamburg, Germany
}

19 December 2007

\section{Abstract}

The FLASH free-electron laser at DESY, Hamburg, has recently been equipped with an infrared electromagnetic undulator. The device provides radiation in the mid- and far-infrared range. It will be used both for electron beam diagnostics purposes and as a powerful source synchronized to the VUV and soft X-ray pulses of the FEL. This report summarizes the measurements that have been performed prior to installation.

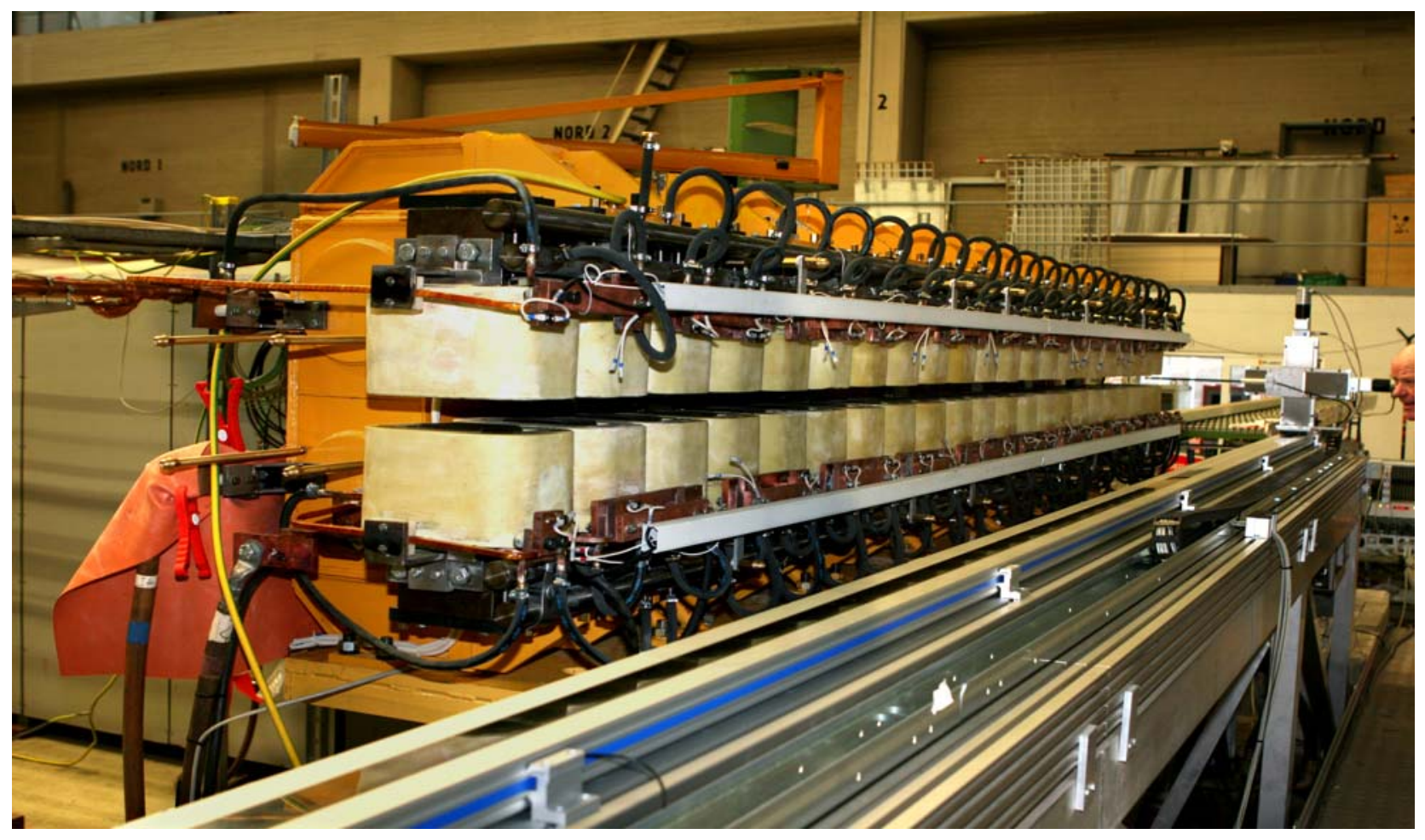




\section{Contents}

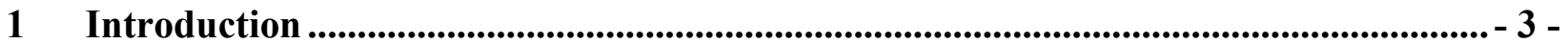

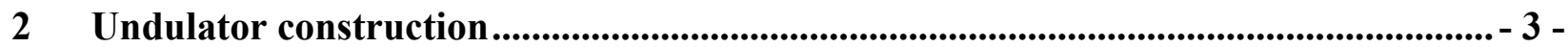

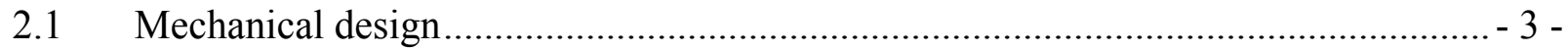

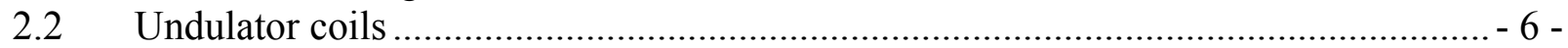

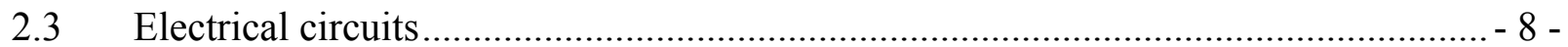

3 Magnetic measurements at JINR................................................................... 10 -

3.1 Measurement bench.................................................................................... 10 -

3.2 Goals of the magnetic field measurements and correction ...................................... 13 -

3.3 Undulator magnetization curve ...................................................................... 13 -

3.4 Minimization of the first field integral in the regular undulator periods .................. 14 -

3.5 Final correction of field integrals and second integral distribution .......................... 16 -

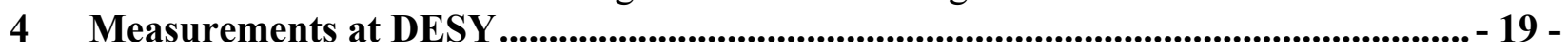

4.1 Magnetic measurement bench.................................................................... 19 -

4.2 Check of reproducibility................................................................................. 20 -

4.3 Field measurements at $435 \mathrm{~A}$ with thermal isolation............................................. 20 -

4.4 Fine tuning of the first and second field integral .............................................. 22 -

$4.53 \mathrm{~d}$ field mapping........................................................................................... 22 -

4.6 Transverse field distributions ............................................................................ 24 -

$4.7 \quad$ Temperature transients ..................................................................................... 26 -

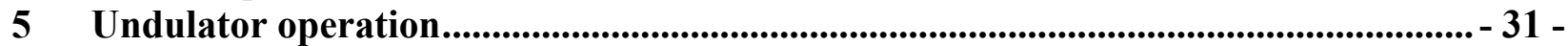

$5.1 \quad$ Corrector coil settings ...................................................................................... 31 -

5.2 Procedure for regime change, cycling procedure................................................ 32 -

5.3 Degaussing procedure .......................................................................................... - 34 -

A Referencing of tuning circuitry ....................................................................................... - 36 -

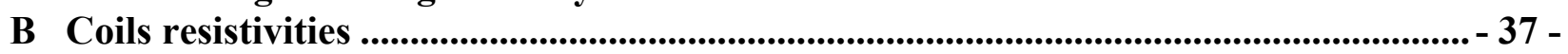

C Magnetization data for pole-pair 11 ..................................................................................... - 38 -

D Magnetic field integrals........................................................................................................... - 41 -

Acknowledgments ..................................................................................................................................... - 44 - 


\section{Introduction}

The FLASH free-electron laser at DESY, Hamburg, has been equipped during the summer 2007 shutdown with an infrared electromagnetic undulator. The device is tunable over a K-parameter range from 1 to 44 , providing radiation up to $200 \mu \mathrm{m}$ at $500 \mathrm{MeV}$ and up to $50 \mu \mathrm{m}$ at $1 \mathrm{GeV}$.

The undulator was manufactured by the Joint Institute for Nuclear Research (JINR) in Dubna, the design being closely adapted to the installation requirements in the FLASH tunnel. Initial functioning tests and characterizations were also undertaken at JINR, followed by more extensive measurements at DESY.

This report summarizes the undulator construction and all measurements that have been performed prior to installation in the FLASH tunnel at JINR and in the magnetic measurement hall at DESY.

\section{Undulator construction}

The undulator is a planar electromagnetic device with 9 full periods, each $40 \mathrm{~cm}$ long. The main parameters are listed in Table 1, a drawing of the undulator integrated into the FLASH tunnel is shown in Figure 1. Figure 2 shows the general design of the undulator. In the following, reference is made to individual poles (the undulator has 44 poles, 22 on upper and lower yoke), to the 22 pole pairs consisting of one upper and one lower pole, and to periods of which the undulator has 9 full ones, each consisting of 2 upper and 2 lower poles. The poles are numbered, starting at the top pole upstream of the electron beam (on the right in Figure 2) and then alternating between up and down.

A high maximum field of $1.1 \mathrm{~T}$ is required to reach sufficiently long wavelengths. For the given period length of $40 \mathrm{~cm}$ and mechanical constraints, this results in a strongly oversaturated field in the yoke. To stay in the linear regime, a yoke thickness of about $250 \mathrm{~mm}$ would be required, but, due to restrictions on weight (imposed by the available lifting equipment) and power consumption, this could not be realized. A yoke thickness of $150 \mathrm{~mm}$ was chosen, yielding an oversaturated magnetic field in the steel yoke of 1.9-2.1 T.

\subsection{Mechanical design}

The magnetic layout of the undulator (Figure 2) consists of 9 regular periods of $400 \mathrm{~mm}$ length and special end poles.

The undulator magnetic yoke is made from two ferromagnetic girders of type 1010 plain carbon steel. The poles are milled to $50 \mu \mathrm{m}$ precision, each is $100 \mathrm{~mm}$ wide. The yokes are supported by a C-shaped frame made from non-magnetic steel, limiting a change of undulator gap due to magnetic forces to less than $20 \mu \mathrm{m}$. Alignment marks are mounted on the top yoke. The $\mathrm{C}$-shape ensures a free access to the undulator gap from one side.

The excitation coils are wound around the poles. The coils of top and bottom girders are coupled sequentially and powered by a single supply. The first and second poles at both ends have a different number of conductor turns than the main poles. 


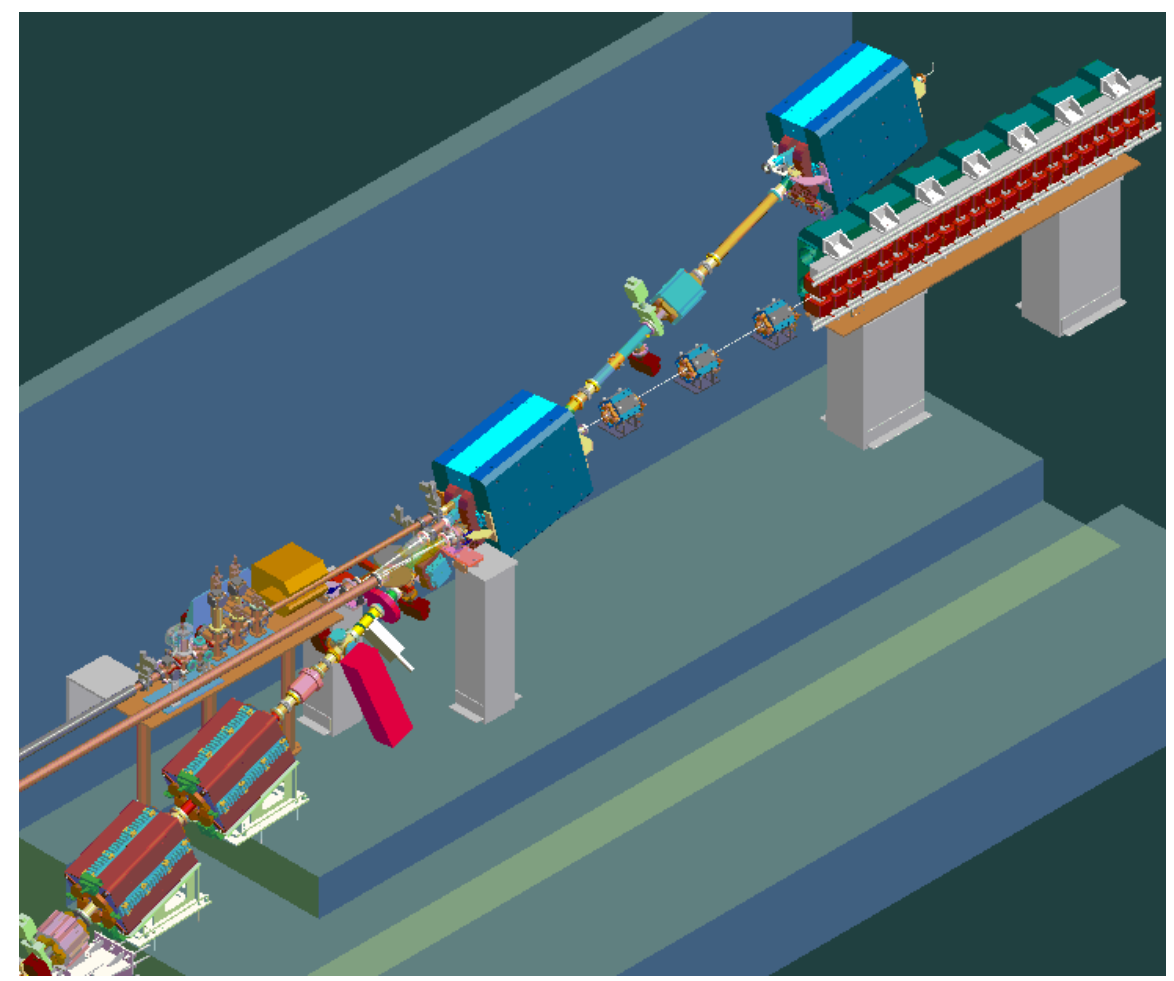

Figure $13 d$ view of the infrared undulator in the FLASH tunnel

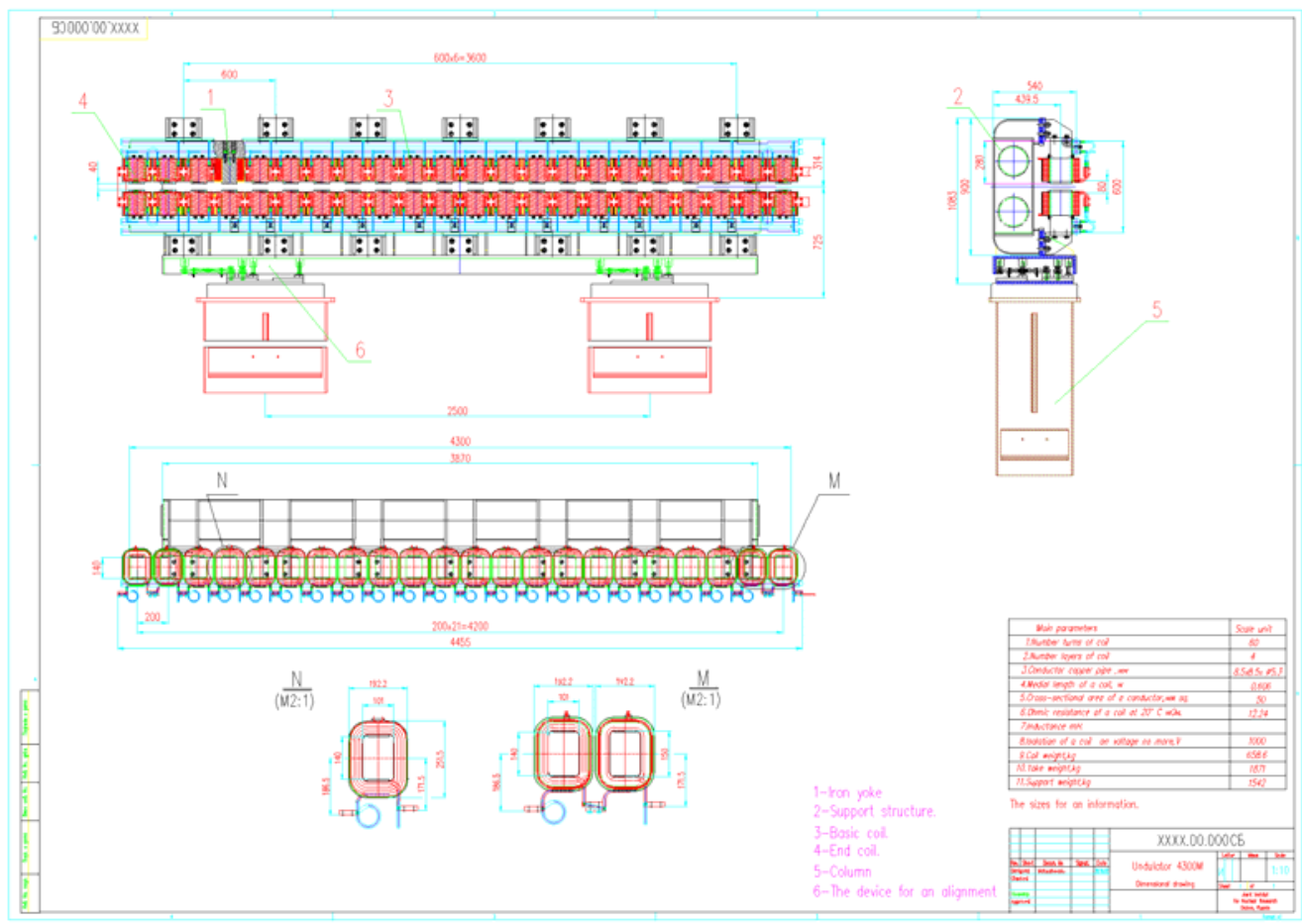

Figure 2 General design of the infrared undulator 
Table 1 Design parameters of the infrared undulator

\section{Parameter}

\begin{tabular}{|c|c|}
\hline Type & Electromagnetic \\
\hline Gap & $40 \mathrm{~mm}$ \\
\hline Period length & $40 \mathrm{~cm}$ \\
\hline Pole length/width & $10 / 14 \mathrm{~cm}$ \\
\hline Number of full periods & 9 \\
\hline Number of poles & 44 \\
\hline End termination pattern & $+1 / 8,-1 / 2,+1, \ldots,-1,+1 / 2,-1 / 8$ \\
\hline Iron yoke length & $4.3 \mathrm{~m}$ \\
\hline Overall length including coils & $4.455 \mathrm{~m}$ \\
\hline Maximum field & $1.2 \mathrm{~T}$ \\
\hline First integral & $<2 \cdot 10^{-4} \mathrm{Tm}$ \\
\hline Second integral & $<2 \cdot 10^{-4} \mathrm{Tm}^{2}$ \\
\hline Maximum K-value & 49 \\
\hline Good field region & $\pm 10 \mathrm{~mm}$ \\
\hline Total weight & $4490 \mathrm{~kg}$ \\
\hline \multirow{3}{*}{$\begin{aligned} \text { Weight of } & \text { yoke (steel 1010) } \\
& \text { coils (copper) } \\
& \text { support }\end{aligned}$} & $870 \mathrm{~kg}$ \\
\hline & $660 \mathrm{~kg}$ \\
\hline & $960 \mathrm{~kg}$ \\
\hline \multicolumn{2}{|c|}{ - Main undulator coil - } \\
\hline Ampere-turns per coil & $27840 \mathrm{~A}$ \\
\hline Number of turns & 64 \\
\hline Maximum current & $435 \mathrm{~A}$ \\
\hline Conductor cross-section & $8.5 \times 8.5 \mathrm{~mm}^{2} \times \varnothing 5.3 \mathrm{~mm}$ bore \\
\hline Conductor area & $50 \mathrm{~mm}^{2}$ \\
\hline Maximum current density & $8.7 \mathrm{~A} / \mathrm{mm}^{2}$ \\
\hline Number of basic/end coils & $36 / 8$ \\
\hline Resistance (basic coil) & $12.36 \mathrm{~m} \Omega$ \\
\hline Voltage@435 A (basic coil) & $5.2 \mathrm{~V}$ \\
\hline Total resistance & $0.49 \Omega$ \\
\hline Total voltage@435 A & $208 \mathrm{~V}$ \\
\hline Inductance (basic coil) & $0.1 \mathrm{mH}$ \\
\hline Total inductance & $4.0 \mathrm{mH}$ \\
\hline Maximum magnetic force & $23700 \mathrm{~kg}$ \\
\hline Water pressure (one coil) & 3 bar \\
\hline Cooling water flow (one coil) & $2.25 \mathrm{l} / \mathrm{min}$ \\
\hline Total cooling water flow & $100 \mathrm{l} / \mathrm{min}$ \\
\hline Water temperature rise@435 A & $20^{\circ} \mathrm{C}$ \\
\hline Maximum temperature rise (water cut off) & $0.4^{\circ} \mathrm{C} / \mathrm{s}$ \\
\hline Maximum total power & $87 \mathrm{~kW}$ \\
\hline
\end{tabular}




\section{- Edge undulator coils -}

\begin{tabular}{ll} 
Number of turns in first and second coil & $10 / 34$ \\
Maximum current & $435 \mathrm{~A}$ \\
& - Regular corrector coil - \\
Number of correction regular coils & 36 \\
Resistance & $4.1 \Omega$ \\
Maximum current & $2 \mathrm{~A}$ \\
\hline Ampere-turns per coil & $540 \mathrm{~A}$ \\
Number of turns & 270 \\
Correction of magnetic field at $1.2 \mathrm{~T}$ & $12 \mathrm{mT}$ \\
& \\
& - Edge corrector coils - \\
Number of turns in first and second coils & 212 \\
Maximum current & $15 \mathrm{~A}$ \\
Resistance & $0.34 \Omega$ \\
\hline Correction of magnetic field & $60 \mathrm{mT}$
\end{tabular}

\subsection{Undulator coils}

\section{Central main coils}

The pole pairs 5 till 18 have coils consisting of four layers of 16 turns each. The windings are made of square copper pipe with $8.5 \times 8.5 \mathrm{~mm}^{2}$ cross-section and a cooling channel of $5.3 \mathrm{~mm}$ diameter (conductor cross-section $50 \mathrm{~mm}^{2}$ ). At the maximum coil current of $435 \mathrm{~A}$, the current density is $8.7 \mathrm{~A} / \mathrm{mm}^{2}$. The power dissipated by one regular undulator period (four coils) is 2.54 $\mathrm{kW}$ at this current. The insulation thickness between windings is $0.8-1.0 \mathrm{~mm}(0.4-0.5 \mathrm{~mm}$ on each winding). Figure 3 shows the cross-section of such a coil. Each of these coils has additionally 270 turns of correction winding (wire diameter $1 \mathrm{~mm}$, resistance $4.1 \Omega$ ), providing a regulation of the Ampere-turns of up to $2 \%$ of the maximum value. This permits to compensate perturbations of the magnetic field related to imperfections of the magnetic system. The correction windings are isolated by heat-resistant enamel double coating.

\section{End coils}

The first and last pair of coils have only $1 / 8$ of the turns of the central main coils ( 1 conductor layer, 8 turns), the second and second-last 1/2 (three conductor layers, 32 turns), see Figure 4 and Figure 5. This allows a basic field integral compensation with a minimal corrector coil current in a wide magnetic field range. The end coils are made from the same conductor material as the main coils and power in series with them. The optimum number of turns does not correspond to the usual ratio of $1 / 4$ and $3 / 4$, as this would result in a more difficult field integral compensation.

The correction windings for the end coils are made from 212 turns of copper wire of $2.5 \mathrm{~mm}$ diameter. The resistance is $0.34 \Omega$, the maximum allowable current $15 \mathrm{~A}$. The correction winding on the first pole pair can provide a field correction up to $60 \%$ of its maximum value without correction, the winding on the second pole pair up to $18 \%$. 
The main circuit of all 44 coils is powered by one DESY standard power supply MK 506/4. Due to the oversaturated magnetic field in the yoke at high excitation, the field in the centre of the undulator gap depends on the individual position of each coil. Therefore, each coil position can be adjusted mechanically in the vertical direction within about $1 \mathrm{~mm}$ to compensate positioning errors.

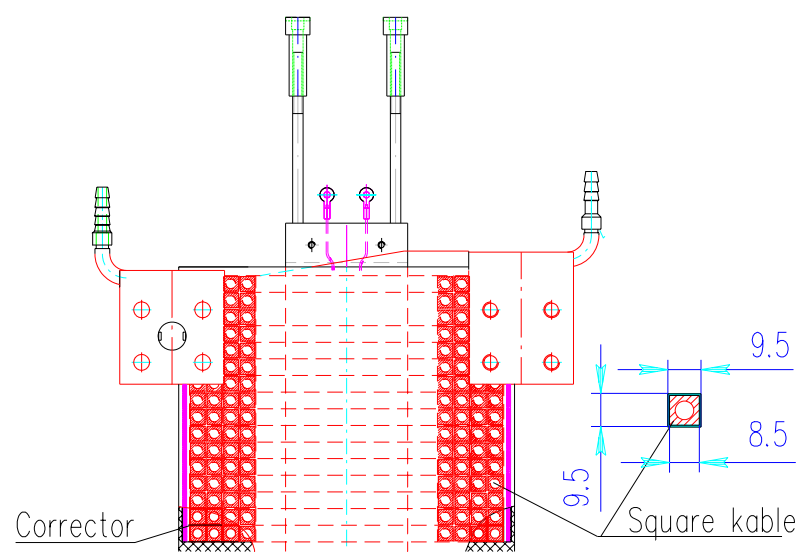

Figure 3 Coil of regular undulator structure with vertical mechanical adjuster

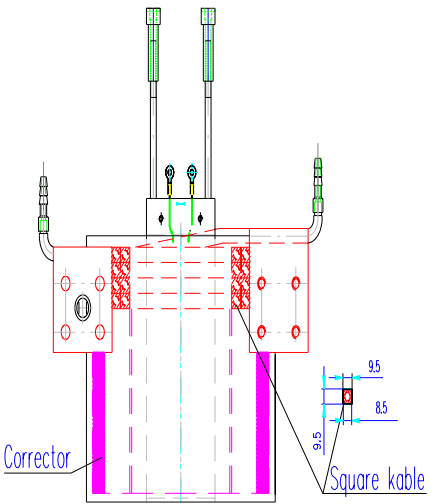

Figure 4 First coil

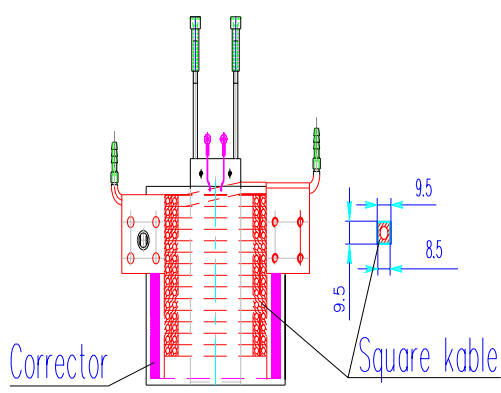

Figure 5 Second coil 


\subsection{Electrical circuits}

The electric schematics of the correction coil circuits is shown in Figure 6. The switches SA1 short-circuit the corresponding coil pair (always one upper and one lower coil), the switches SA2 reverse their magnetic field. The variable resistors Rx are connected parallel to the series of the two coils. These settings are referenced in case they are lost or parts have to be replaced, see Appendix A.

The wiring of the PT-100 temperature sensors ${ }^{1}$ and pilotherm switches and their respective connectors is shown in Figure 7. The top and bottom pilotherm switches are connected in one series, each.
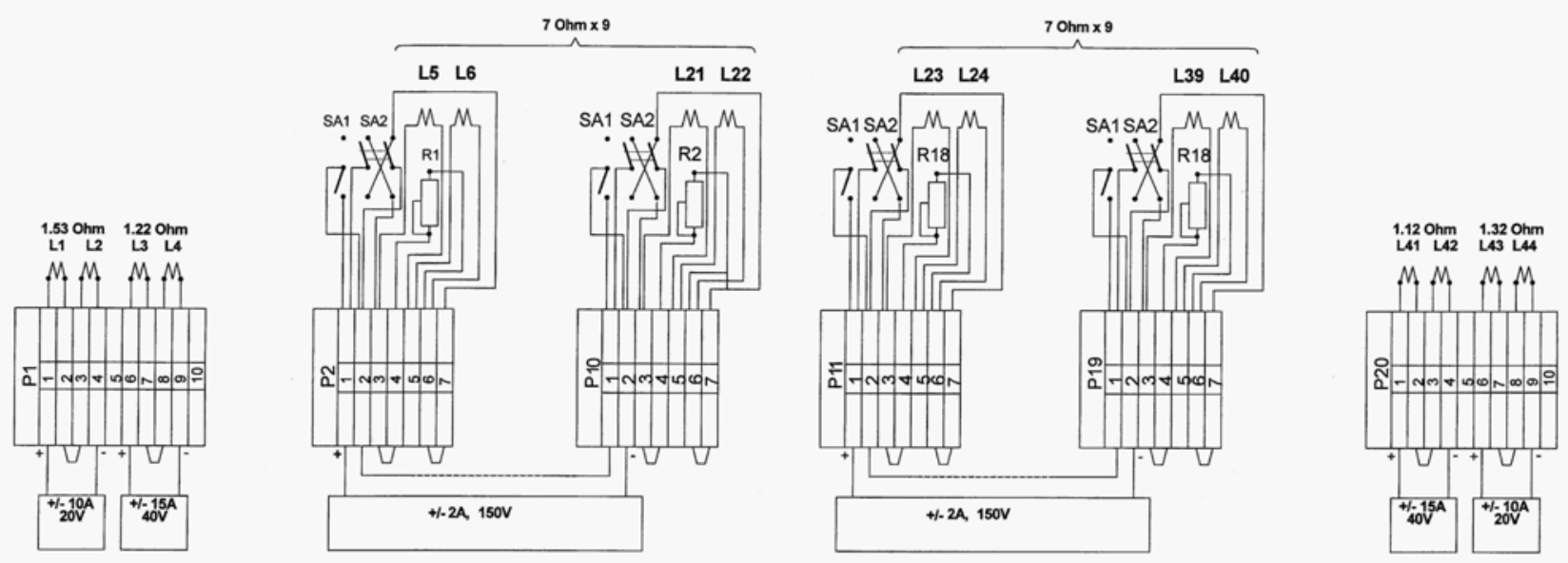

Figure 6 Schematics of correction coils

\footnotetext{
${ }^{1}$ Microtherm, Pforzheim, Germany, Model EF-1 (two wire) with M4 thread
} 

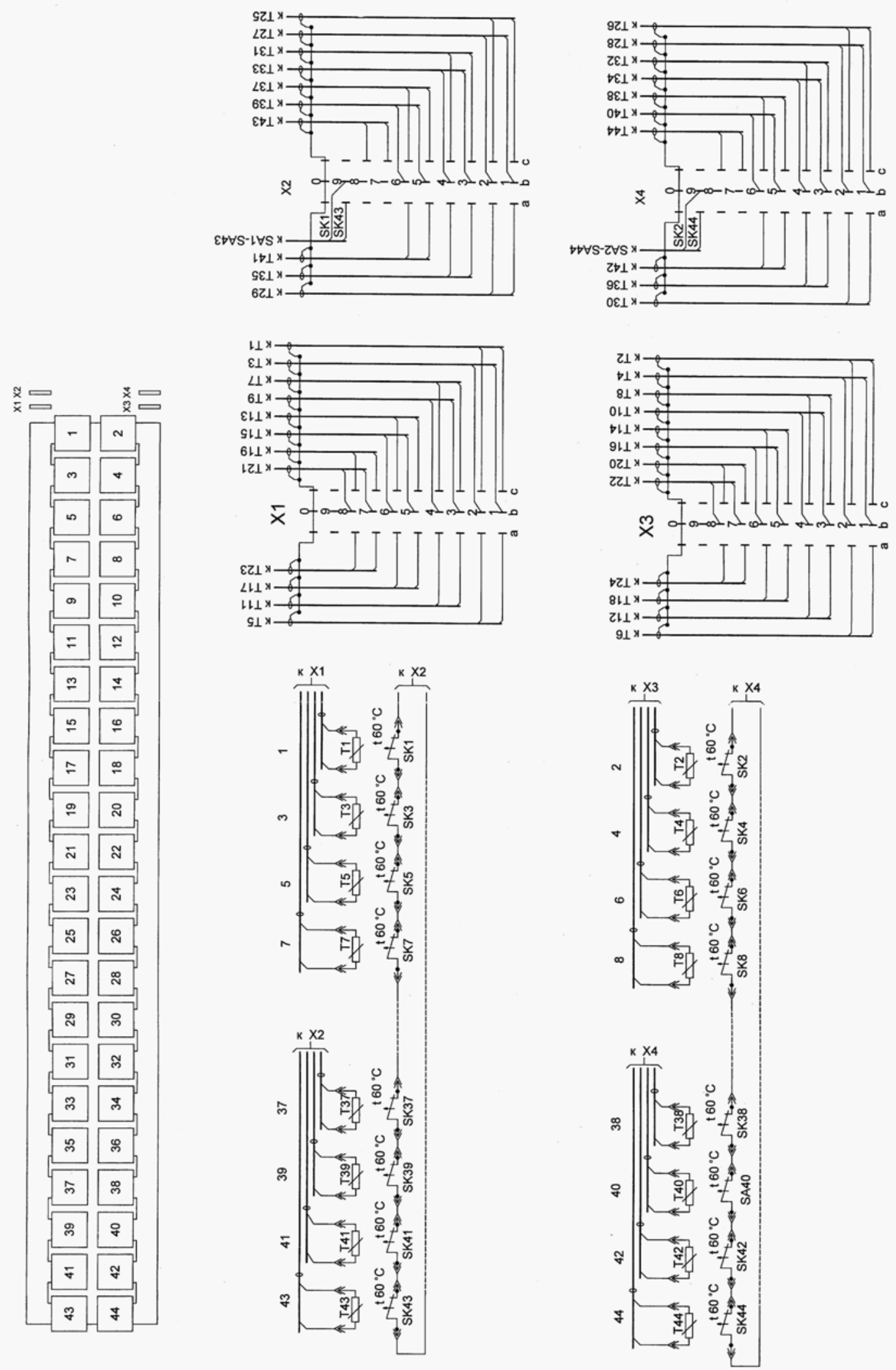

Figure 7 Connection of pilotherm switches and PT-100 temperature sensors 


\section{Magnetic measurements at JINR}

\subsection{Measurement bench}

The mechanical part of the JINR measurement bench is based on equipment delivered from NIKHEF, Amsterdam. The bench is shown in Figure 8. The 3d measurement head moves in longitudinal direction on rails over a distance of $4.7 \mathrm{~m}$. At the end of the measurement arm the Hall probe is fixed (Figure 9).

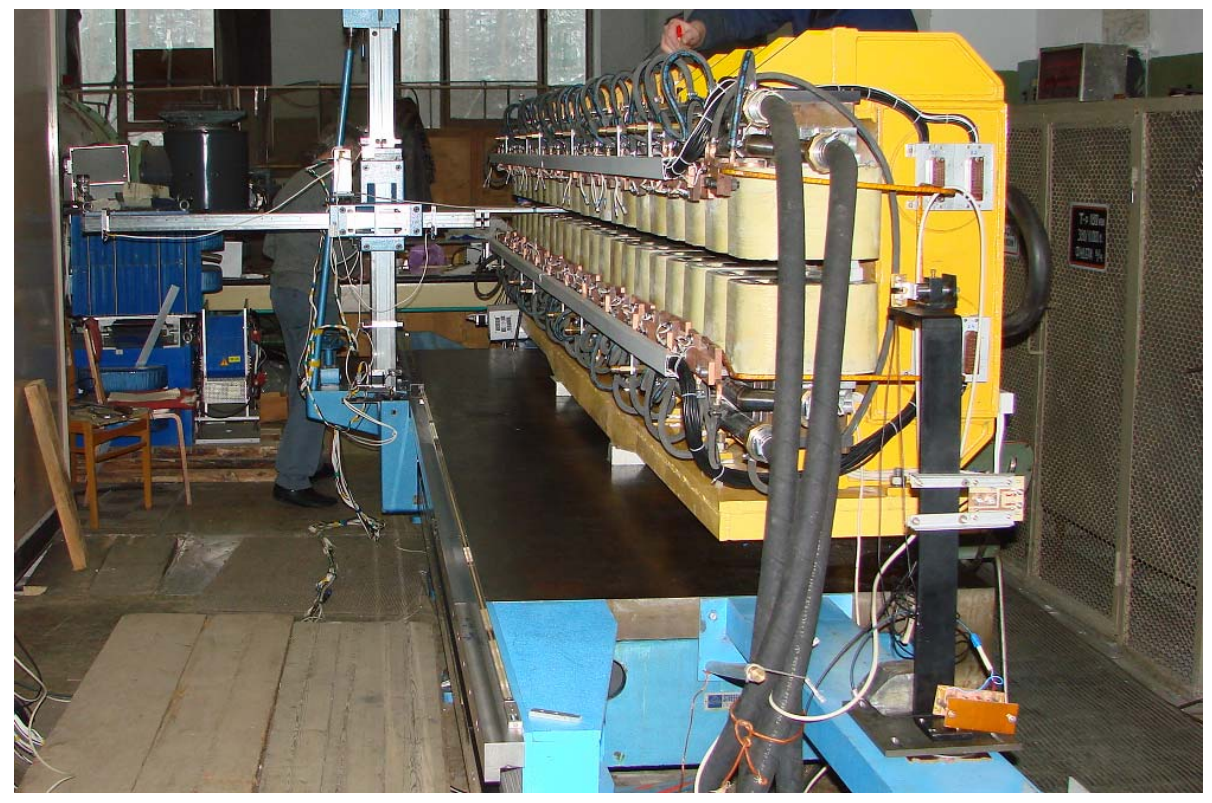

Figure 8 View of the measurement bench

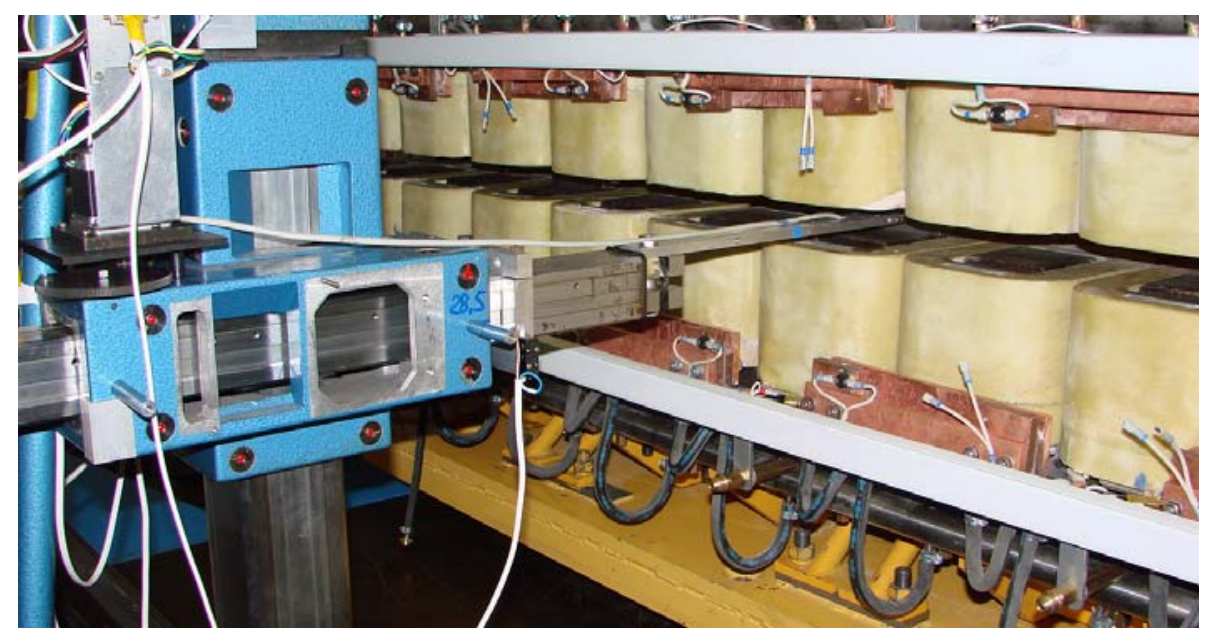

Figure 9 Measurement arm with Hall probe 
The measurement arm and head are moved with 3 stepping motors (Figure 10). In longitudinal $\mathrm{z}$ direction the position of the measurement arm is detected absolutely by a high accuracy (few $\mu \mathrm{m}$ ) linear encoder (HEIDENHAIN LIDA-485). For magnetic field mapping a homemade Hall magnetometer HM-16 (Figure 11) was used. The reference magnetic field was measured by a homemade nuclear magnetic resonance magnetometer NM-23 (Figure 12) and a Hall probe MX-12. The probes for both reference magnetometers were installed in the gap of the third pair of undulator poles.

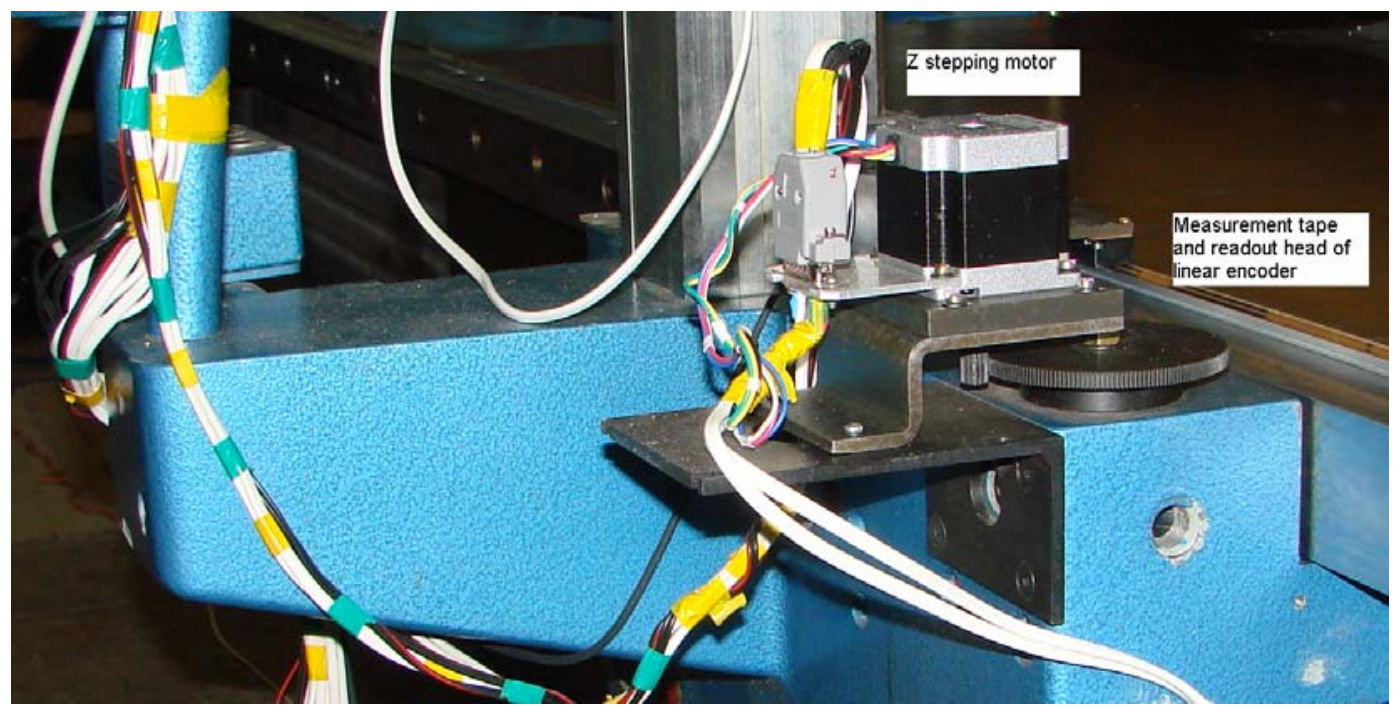

Figure $10 \mathrm{Z}$ stepping motor and linear encoder

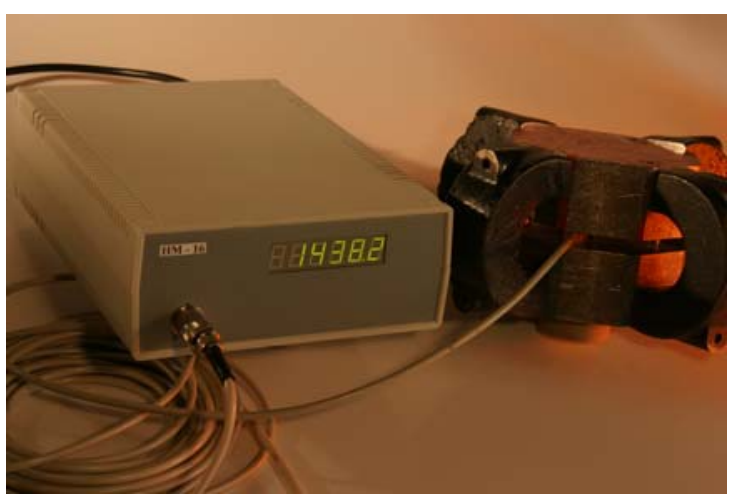

Figure 11 HM-16 Hall magnetometer

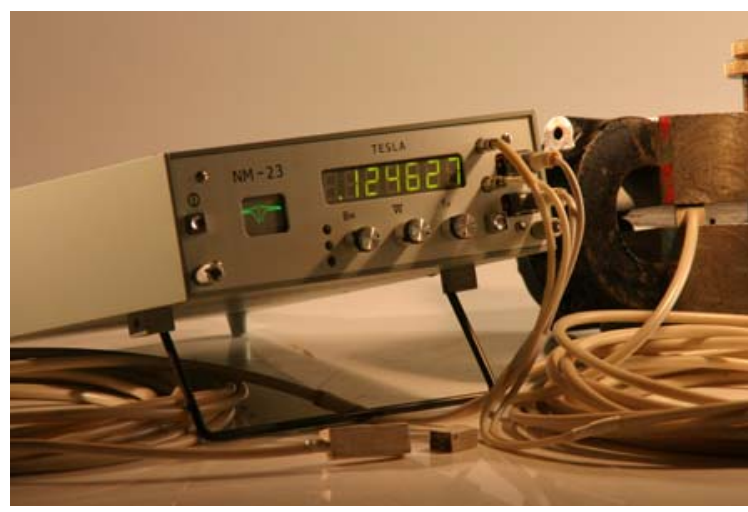

Figure 12 NM-23 NMR magnetometer

All electronic equipment except the magnetometer MX-12 was controlled by a PC, as shown in Figure 13. The acquired date included time, $\mathrm{x}, \mathrm{y}, \mathrm{z}$ coordinates, and magnetic field measured by the scanning and reference probes. One measurement pass (longitudinal extend $470 \mathrm{~cm}$, step $0.5 \mathrm{~cm}$ ) required about 2 hours, due to mainly the heavy measurement head and the required delay of 5 seconds for the Hall measurement to settle to a stable value. 


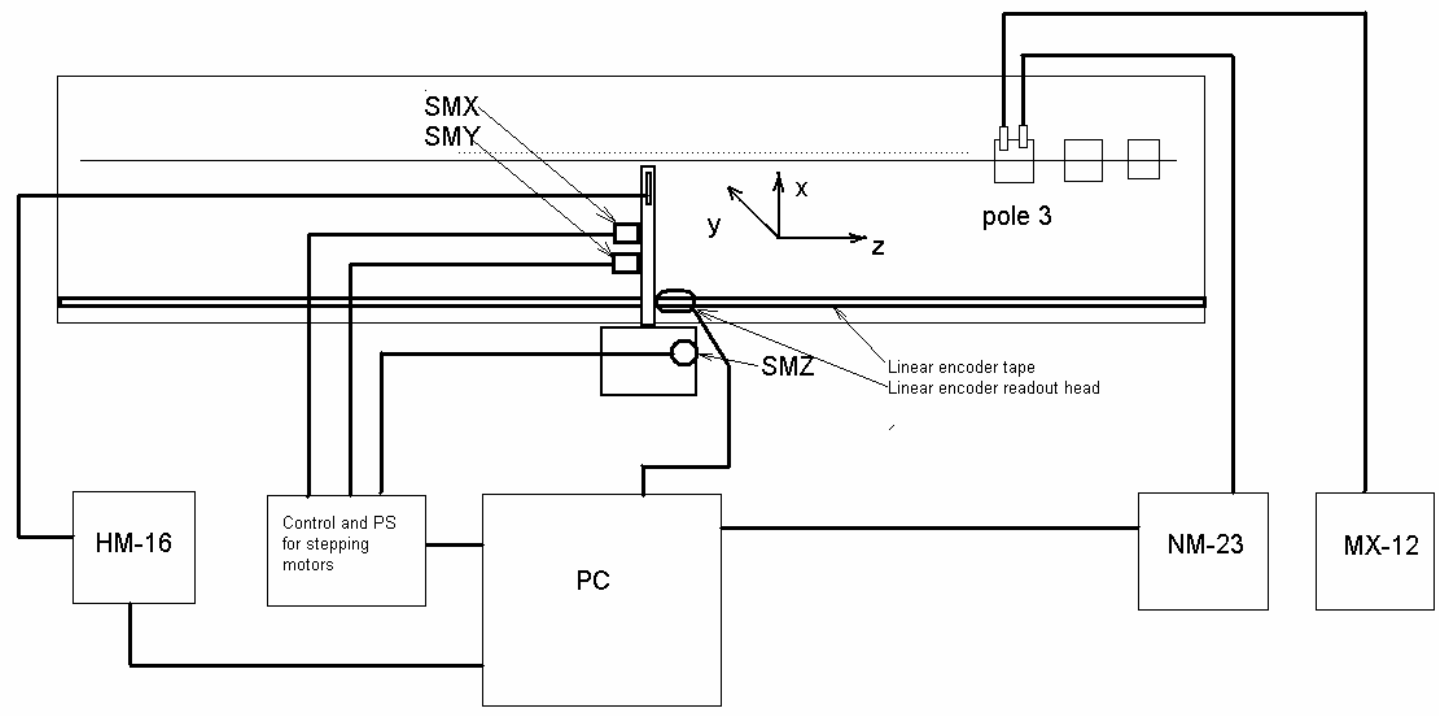

Figure 13 Scheme of the measurement bench hardware

The undulator main coil was excited by a Bruker power supply ( $450 \mathrm{~A}, 120 \mathrm{~V}$, stability $10^{-5}$ ). Due to the coil resistance, its voltage limit was reached at 200 A excitation current. Correction by the reference probe was not needed for this supply. For excitation currents between $250 \mathrm{~A}$ and $380 \mathrm{~A}$, a motor-generator with stability $\sim 10^{-3}$ was used, requiring correction by the reference probe. Correctors coils were excited with power supplies providing $10^{-3}$ stability (Figure 14).

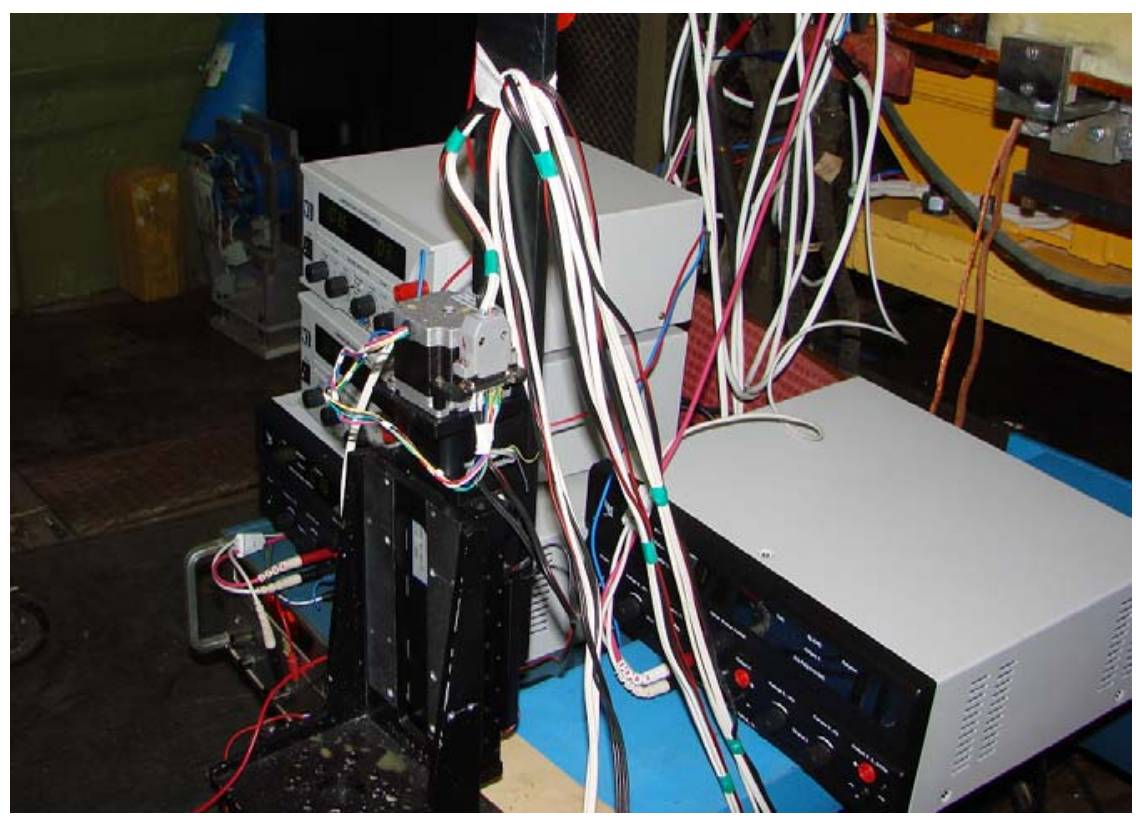

Figure 14 Correction coils power supplies 


\subsection{Goals of the magnetic field measurements and correction}

Initial testing at JINR was geared towards corrections of mechanical, electrical and water cooling problems. Then, a full test of the magnet was done and the system reliability checked. The tuning procedure was along the following guide lines:

- Final first field integral less than $100-200 \mathrm{G} \cdot \mathrm{cm}$, final second field integral less than 200 $\mathrm{kG} \cdot \mathrm{cm}^{2}$.

- First field integral in each regular undulator period less than $100-200 \mathrm{G} \cdot \mathrm{cm}$.

- Second field integral (electron trajectory) along the undulator has an axis as parallel as possible to the undulator axis.

- The above requirements should be fulfilled in the full range of main coil excitation currents between 0 and $435 \mathrm{~A}$.

- Minimization of the number of required correction power supplies.

- The tuning should be reproducible within a deviation of less than $50 \mathrm{G} \cdot \mathrm{cm}$ and $5 \mathrm{kG} \cdot \mathrm{cm}^{2}$, respectively.

\subsection{Undulator magnetization curve}

The measured magnetization curve (central field, pole pair 4) shows excellent agreement with simulation results obtained with the TOSCA code (Figure 15).

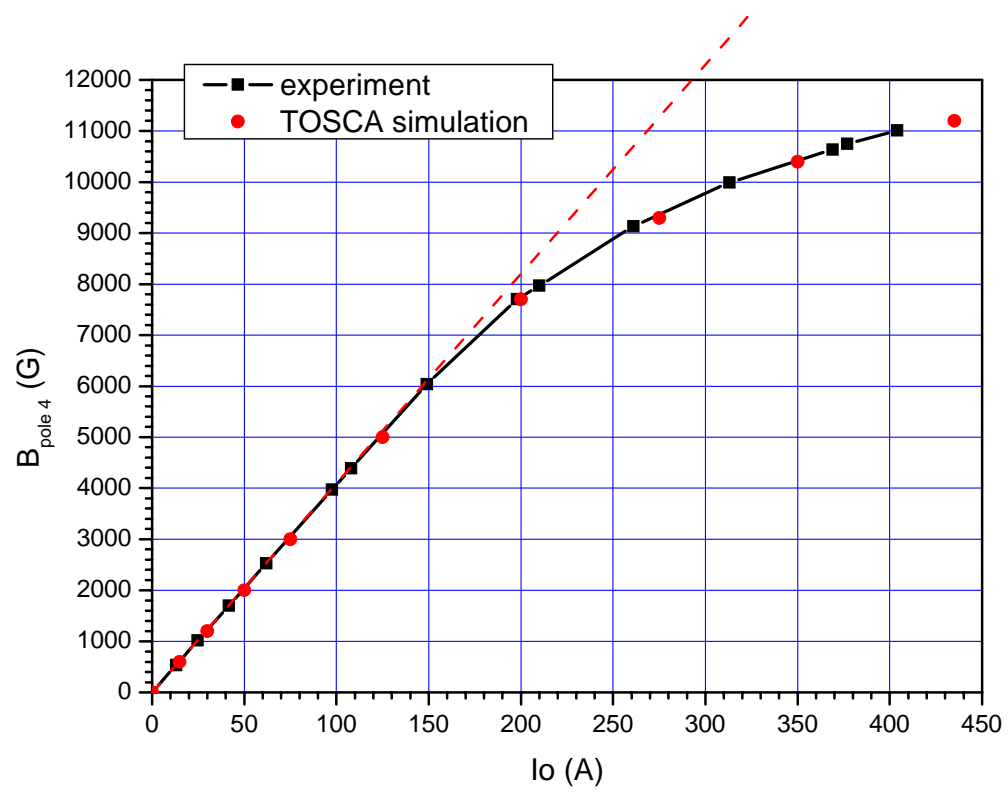

Figure 15 Undulator magnetization curve (pole pair 4) 


\subsection{Minimization of the first field integral in the regular undulator periods}

The first field integral minimization was done in an iterative way by adjusting the values of the correction coil shunt resistors. All regular undulator correctors (poles 3-20) were excited by one power supply in series. The correction was first optimized for a main coil current of $200 \mathrm{~A}$. The resistors were tuned at $1 \mathrm{~A}$ correction current. For other main coil currents the value of the regular periods corrector current was then determined which minimized the first field integral. The initial value obtained for the first field integral in the regular periods was $1500 \mathrm{G} \cdot \mathrm{cm}$. The large value results from the difference of the field of individual poles from the average value, see Figure 16. The initial and final values for the first field integral are shown in Figure 17.

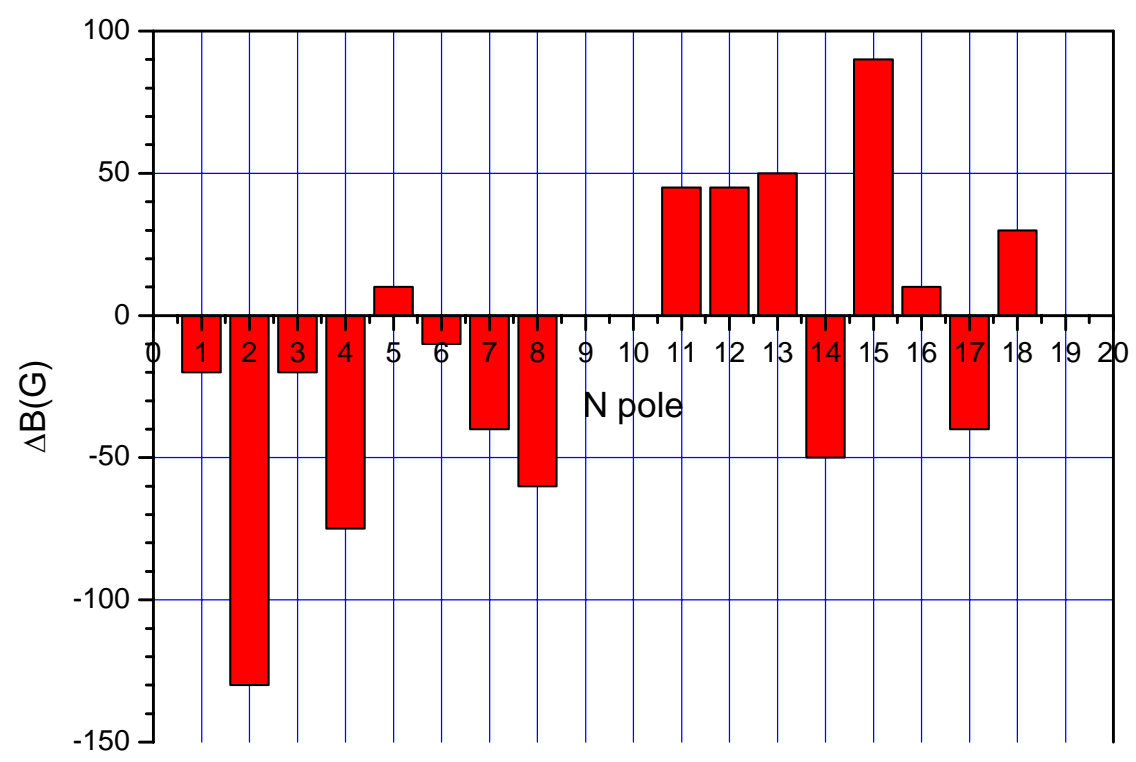

Figure 16 Deviation of the central field for the 18 central pole pairs before tuning 


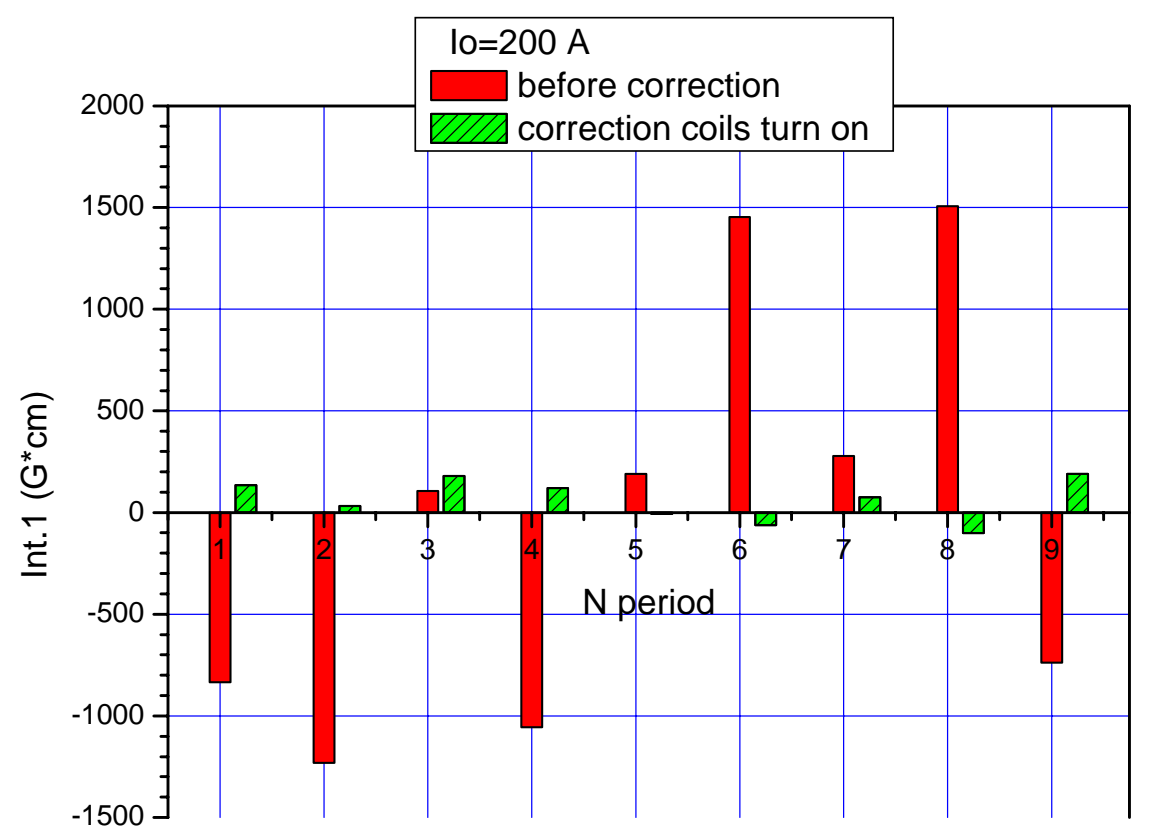

Figure 17 Distribution of the first field integral at $200 \mathrm{~A}$ before and after correction coil tuning

The tuning results for the first field integral for all working regimes shaped at JINR are presented in Figure 18. The maximum value of the regular period correction current was below 1.2 A (Figure 19).

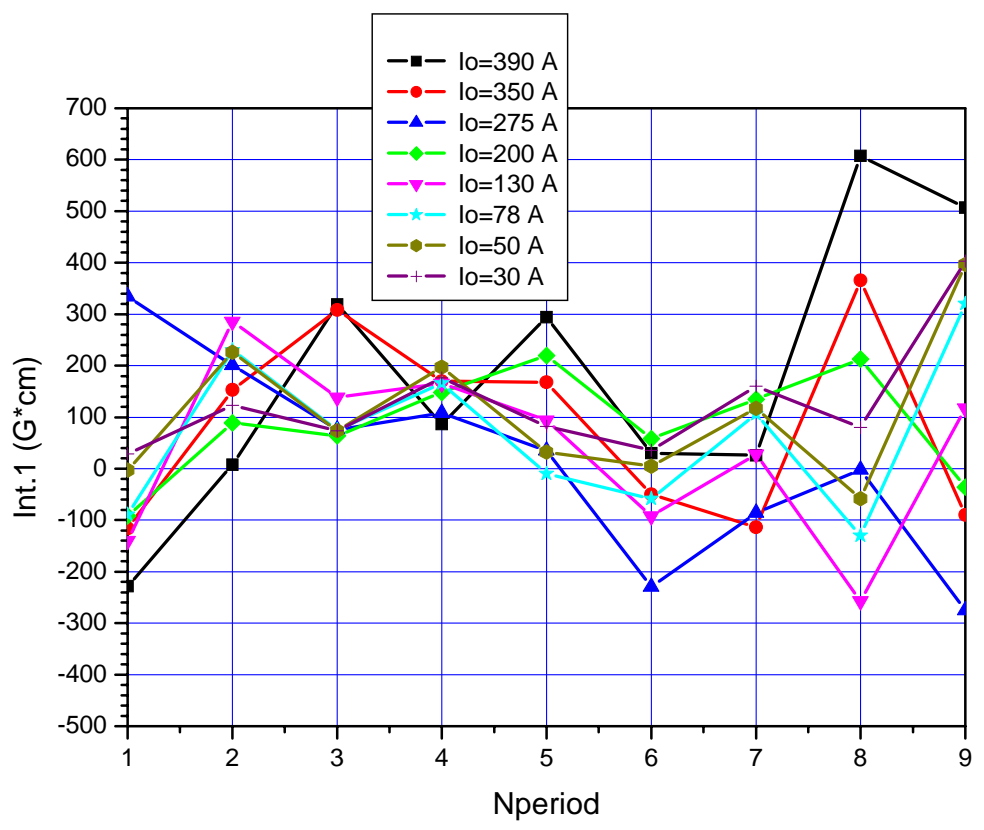

Figure 18 Distribution of the first field integral in the regular undulator periods 


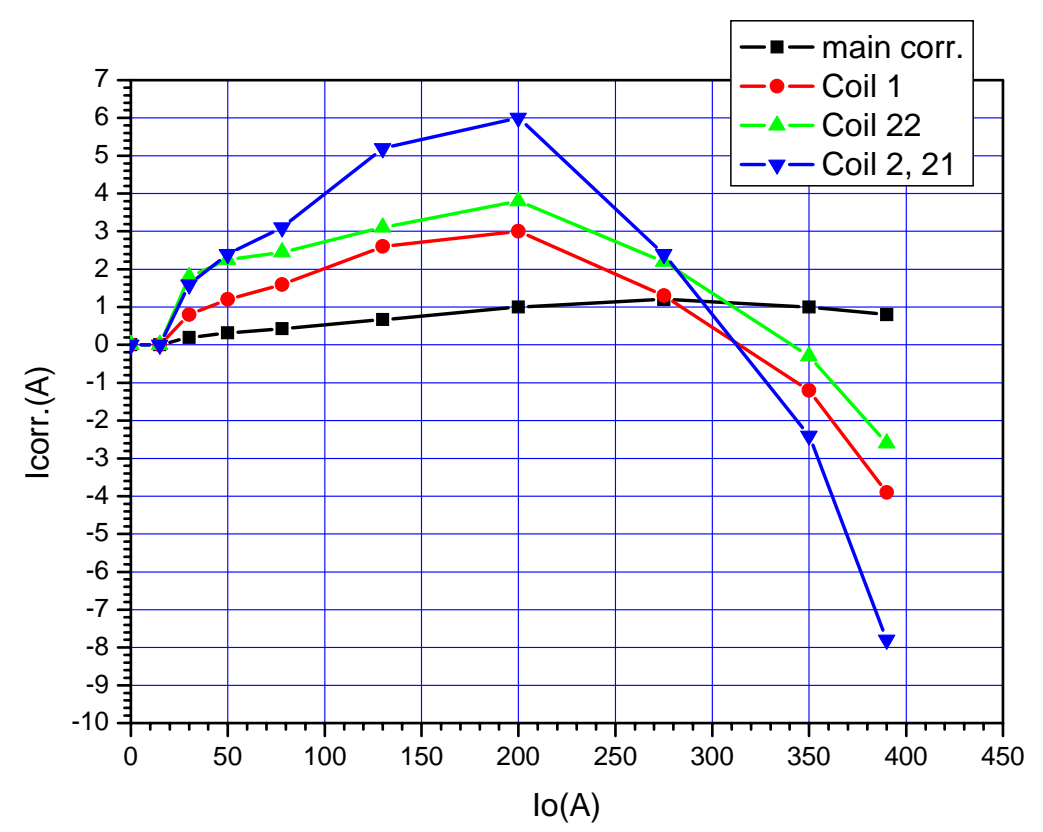

Figure 19 Correction currents for all main coil excitation currents

\subsection{Final correction of field integrals and second integral distribution}

Final first and second field integral correction and minimization was obtained by tuning the corrector currents for the pole pairs 1,2, 21 and 22. The maximal correction current was $8 \mathrm{~A}$. The final first and second field integral is shown in Figure 20 and Figure 21.

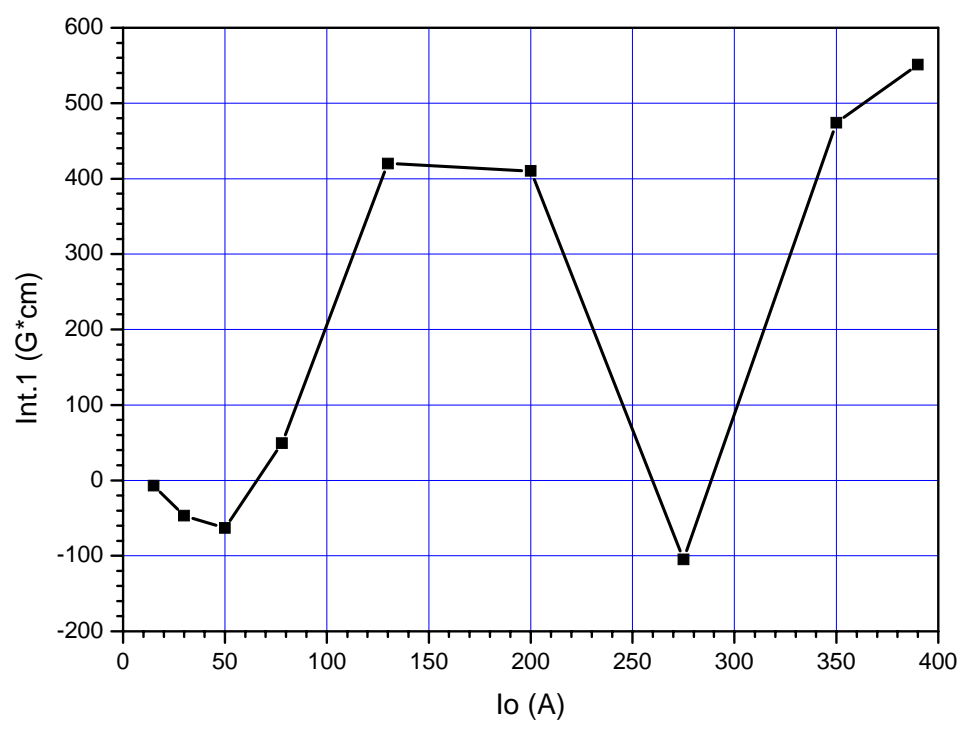

Figure 20 Final first field integral for all main coil excitation currents 


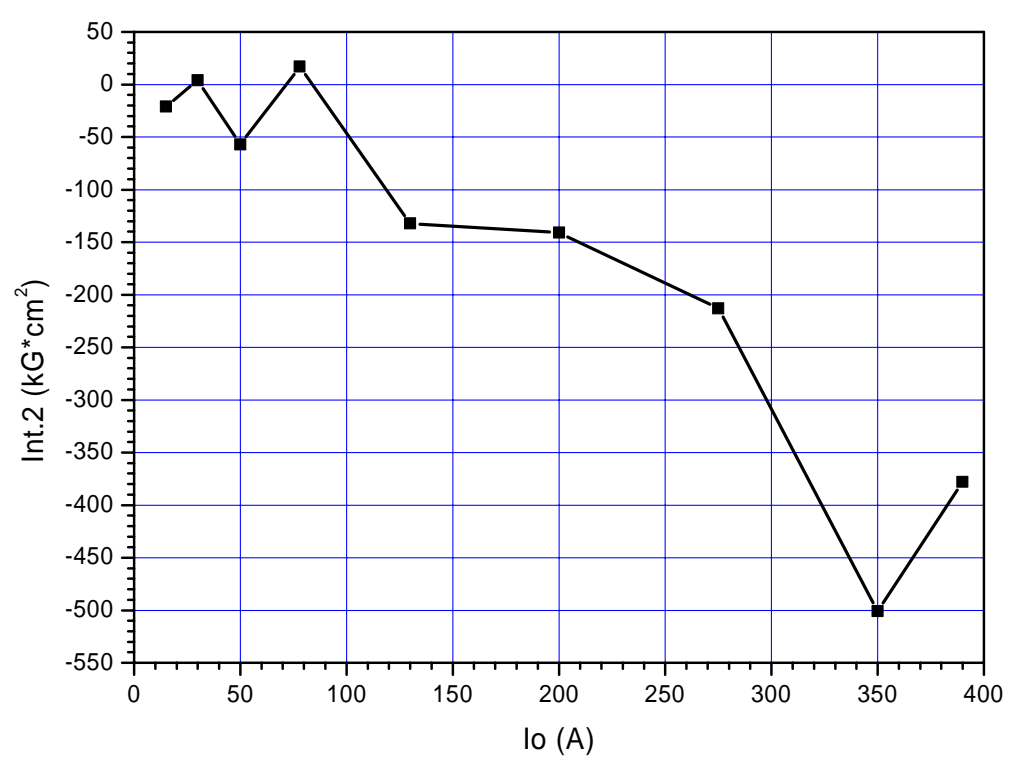

Figure 21 Final second field integral for all main coil excitation currents

The final distributions of the second field integrals are shown in the following figures.
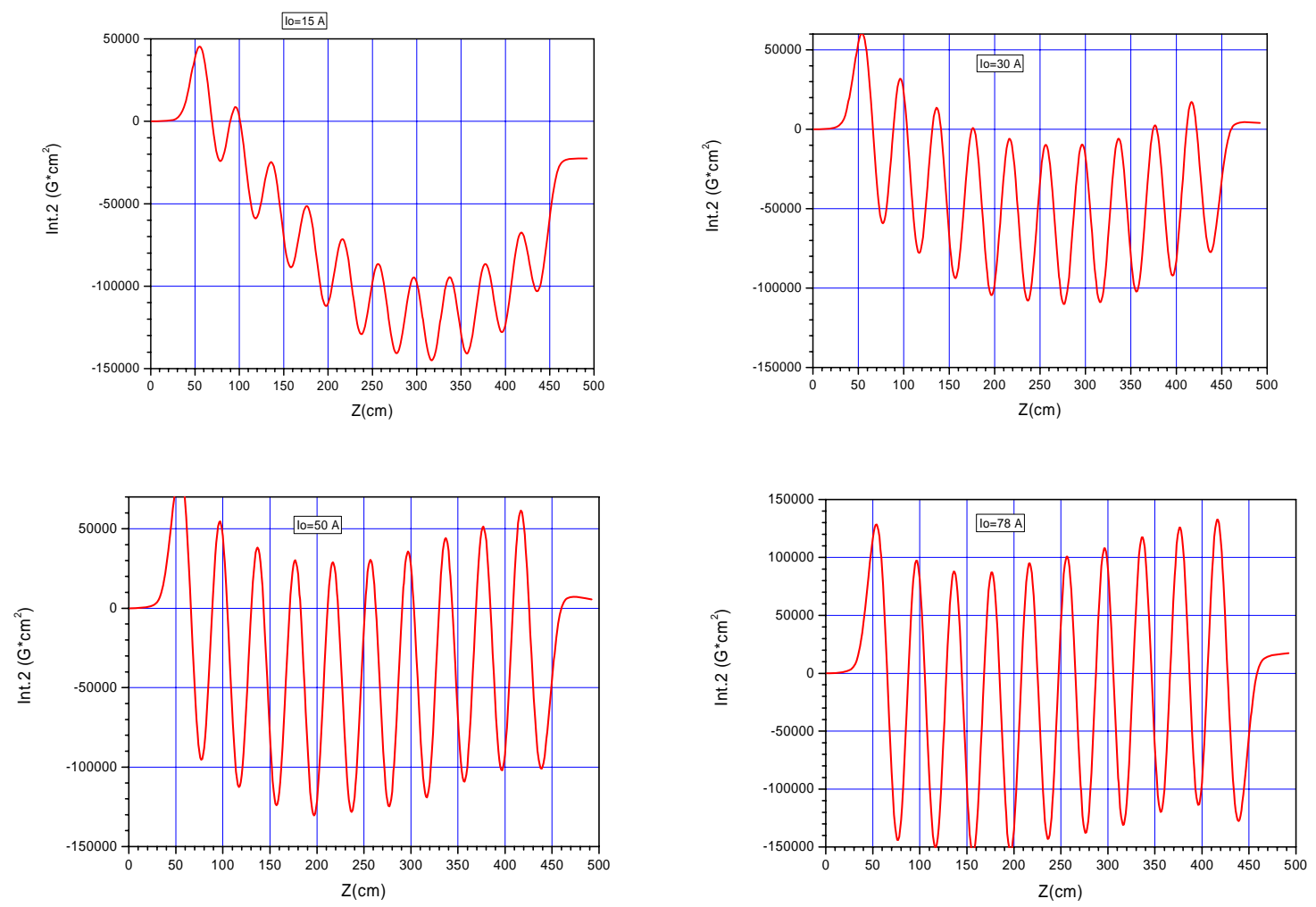

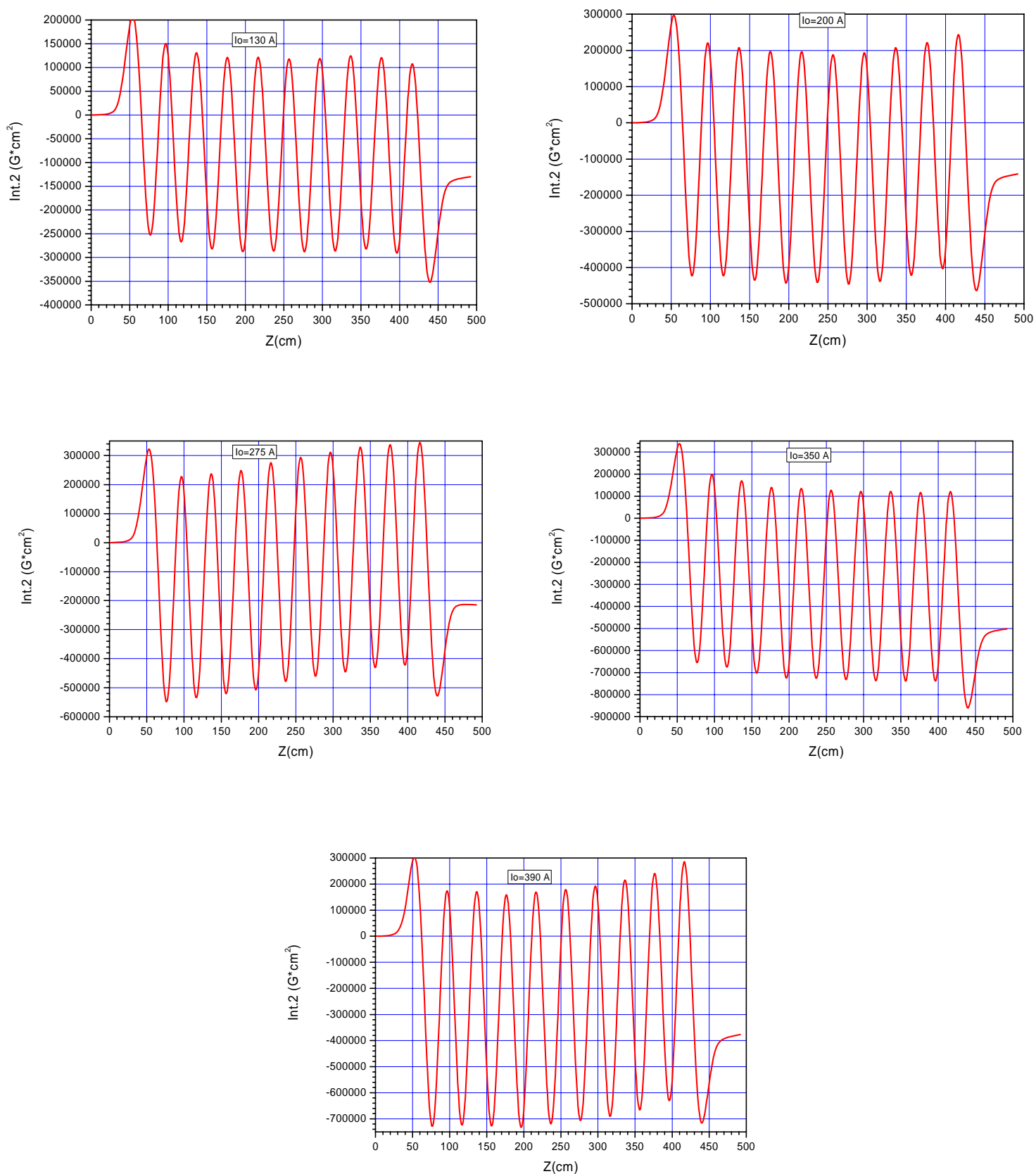


\section{Measurements at DESY}

After shipping the undulator to DESY on truck and ferry via St. Petersburg and Kiel, the first measurements intended to verify that the undulator arrived in good shape, without suffering damage or tuning shifts. As a sufficiently stable power supply was available at JINR only for lower main coil excitations currents, the next step was then finishing the tuning for the remaining currents.

As the field mapping at DESY was significantly more rapid than at JINR, the number of main working regimes was increased from 9 to 22. The procedure of working regimes setting was modified (see Chapter 5). Repeatability of the working regimes was studied and $3 \mathrm{~d}$ maps measured. Repeated measurements of the same regime without changing coil currents have demonstrated an accuracy of determination of the first field integral of $\pm 25 \mathrm{G} \cdot \mathrm{cm}$ and of the second of $\pm 5 \mathrm{kG} \cdot \mathrm{cm}^{2}$. The results of the second field integral shape were very close to the results JINR measurements and a more accurate final value for the first integral was provided at DESY.

\subsection{Magnetic measurement bench}

The $3 \mathrm{~d}$ field-mapper is designed to scan the fields of long slim dipole magnets with C-type cross section. The mechanics consist of a $6 \mathrm{~m}$ long toothed belt drive linear module for the longitudinal motion ( $\mathrm{z}$ ) with an $\mathrm{x}-\mathrm{y}$ stage on top for the transverse directions ${ }^{2}$. The units are driven by conventional 2 phase stepping motors with 400 steps/revolution and allow resolutions of $15 \mu \mathrm{m}$ and $12.5 \mu \mathrm{m}$, respectively. The positioning accuracy in $\mathrm{z}$ is about $\left(0.1 \mathrm{~mm}+10^{-4} \mathrm{z}\right)$ and $10 \mu \mathrm{m}$ in $\mathrm{x}$ and $\mathrm{y}$.

The magnetic field is measured by a precision Hall probe ${ }^{3}$ with an accuracy of $1.2 \times 10^{-4}$. Its reading is corrected for temperature dependence and nonlinearity. It is mounted to a $400 \mathrm{~mm}$ long $8 \mathrm{~mm}$ outer diameter carbon fibre tube and can be oriented as to measure one of the 3 field components. A second identical Hall probe in a fixed position serves as a reference sensor to cope with long term drift effects.

The measuring machine is connected to a rack mounted PC equipped with add-on cards for GPIB bus read-out and motion control ${ }^{4}$. The control program is a LabVIEW application. One pass of $5 \mathrm{~m}$ through the magnet with $5 \mathrm{~mm}$ step width (1001 data points) is completed after about 11 minutes.

The undulator was aligned on the magnetic measurement bench to a precision of $0.5 \mathrm{~mm}$. Pilotherm and water flow interlocks to the main power supply were installed in the same way as for the final tunnel installation.

\footnotetext{
${ }^{2}$ Franke GmbH, Aalen/Germany

${ }^{3}$ Group3 Technology Ltd., Rosebank, New Zealand, Model DTM-151 with sensor MPT-141

${ }^{4}$ National Instruments, Austin, USA
} 


\subsection{Check of reproducibility}

A comparison between second field integrals (electron trajectories) obtained before and after shipping is shown for several main excitation currents in Figure 22 and indicates good reproducibility between measurements and JINR and at DESY for the same undulator tuning.
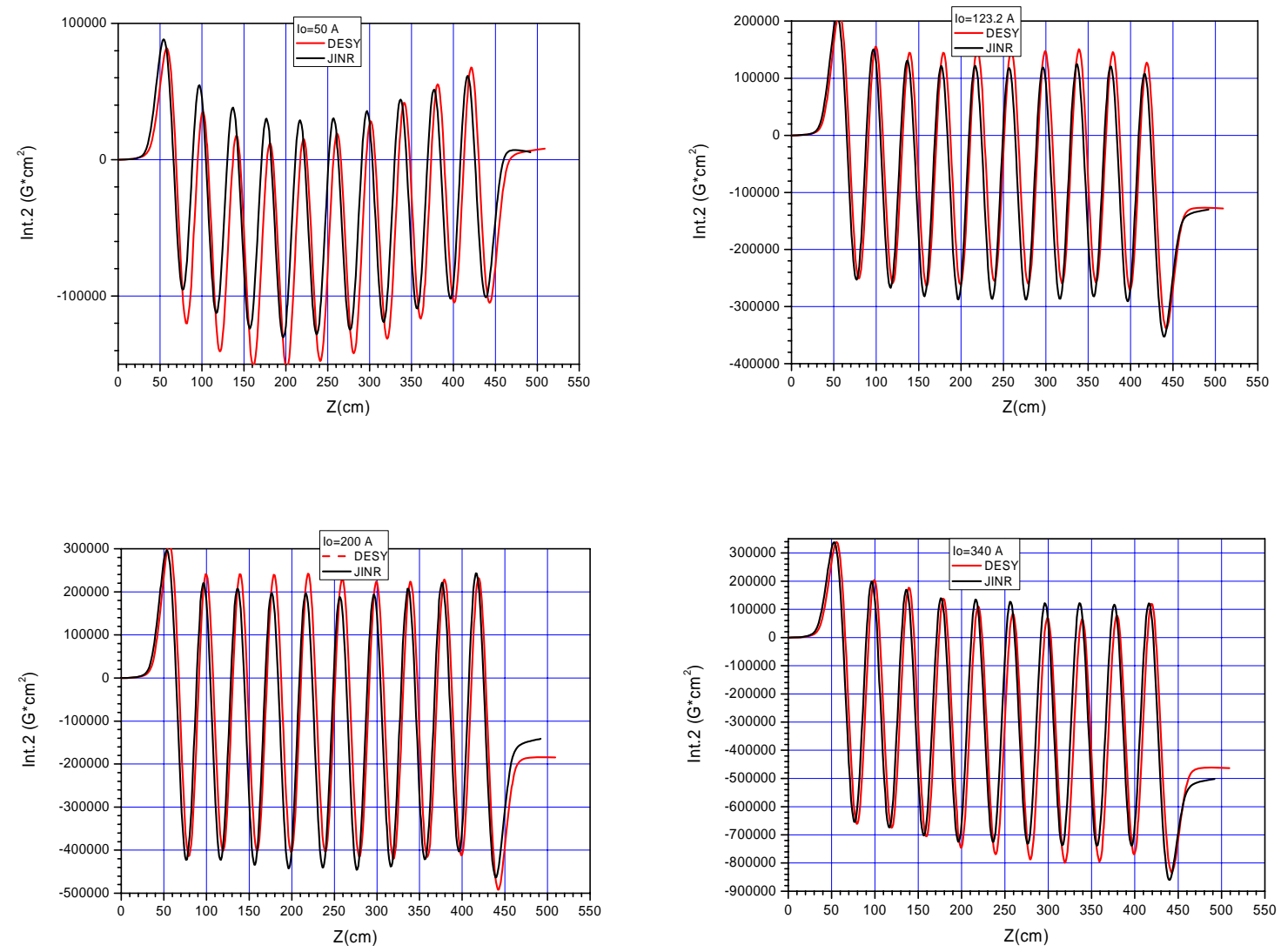

Figure 22 Comparison of second field integrals before and after shipping

\subsection{Field measurements at $435 \mathrm{~A}$ with thermal isolation}

The high power consumption of up to $110 \mathrm{~kW}$ and subsequent heating could possibly require dedicated temperature isolation to reduce the amount of heat dissipated into the environment. From the measured water flow rate and temperature rise, less than a few $\mathrm{kW}$ are not carried away by cooling water. More precision was not possible as the flow rate could not be measured to better than 5\%. Although this is a small number, a thermal shield shown in Figure 23 is available, to be prepared in case higher temperature stability demands in the FLASH tunnel arise in the future.

Within better than $1 \%$ no change in output water temperature was measurable with and without thermal isolation at maximum excitation current and constant water flow rate. As the 
shield certainly reduces any heat transport to the air significantly, less than $1 \mathrm{~kW}$ is actually dissipated into the environment.

The isolation prevents the measurements of field integrals. The Hall probe could only be inserted at several joint points between two layers of the isolation. For one such position centered within one pole pair, the field change over time and with and without thermal isolation has been measured, see Figure 24. The differences are close to the accuracy of the measurement equipment. It also needs to be noted that with isolation present, the Hall probe will be subject to a larger change in air temperature, and thus its temperature coefficient may also start to contribute.

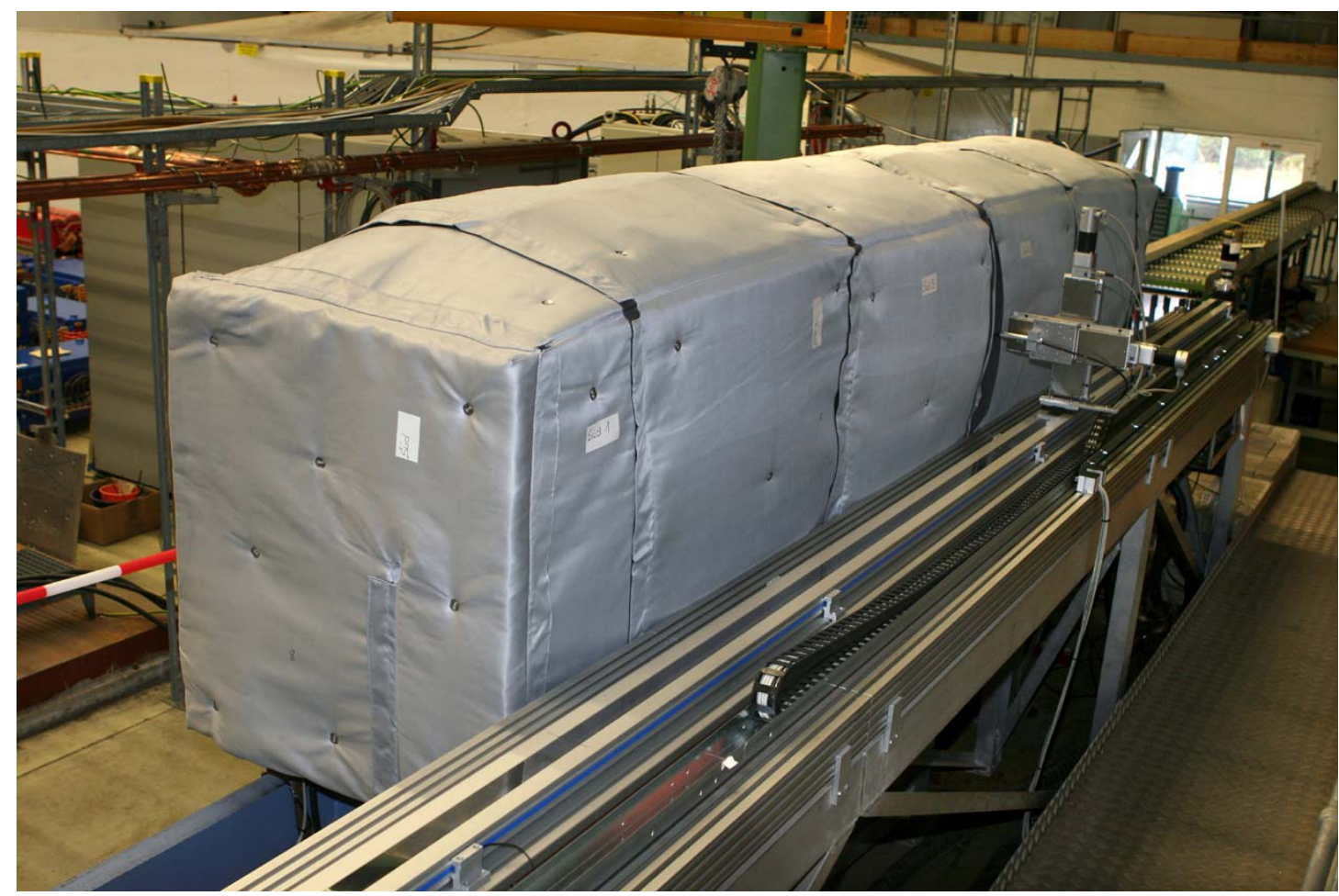

Figure 23 Undulator with thermal shield installed and Hall sensor inserted
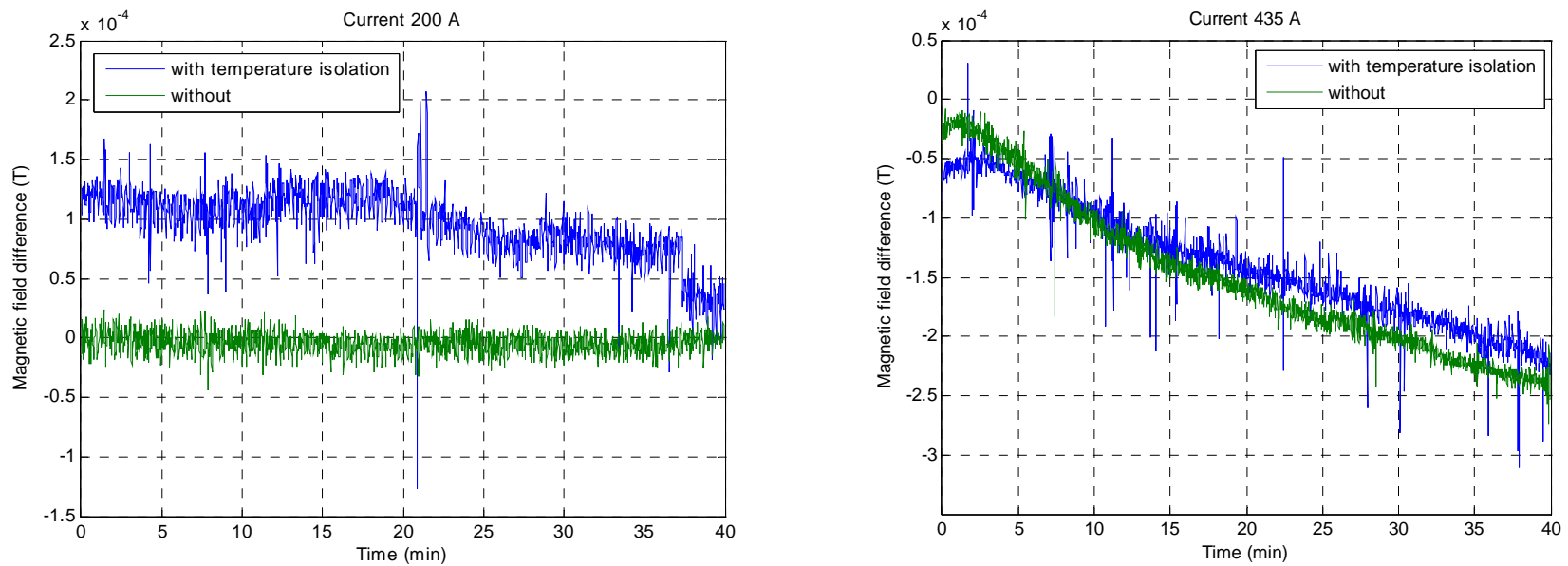

Figure 24 Change of magnetic field with time with and without thermal shield 


\subsection{Fine tuning of the first and second field integral}

The final fine tuning of the first and second field integral was adjusted by using the first and last correctors only. Those correctors have the following responses:

- Current variation in coil 22 changes the first field integral: 0.1 A up -> first integral down by $150 \mathrm{G} \cdot \mathrm{cm}$. It does not influence the second field integral.

- Current variation in coil 1 changes the second field integral but also influences the first one: $0.1 \mathrm{~A}$ up -> second integral down by $70 \mathrm{kG} \cdot \mathrm{cm}^{2}$, first integral down by $60 \mathrm{G} \cdot \mathrm{cm}$.

\section{$4.53 d$ field mapping}

The undulator magnetic field tuning was done using on-axis measurements only. For some regimes, also $3 \mathrm{~d}$ maps of the vertical field component were taken $(\mathrm{x}=-10,-5,0,5,10 \mathrm{~mm}, \mathrm{y}=-5,0,5$ $\mathrm{mm})$. The results of mapping are presented in Figure 25 - Figure 30. The field integral variations are close to the limits of the measurement accuracy.
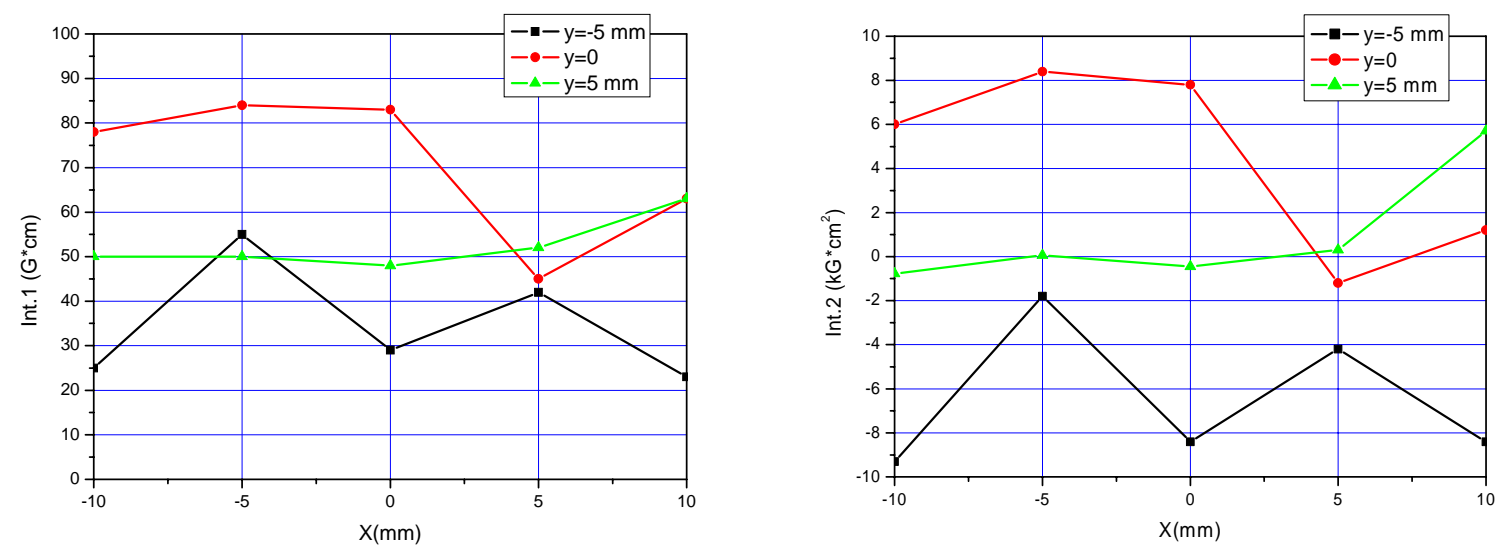

Figure 25 Field integrals at 50 A main coil excitation 

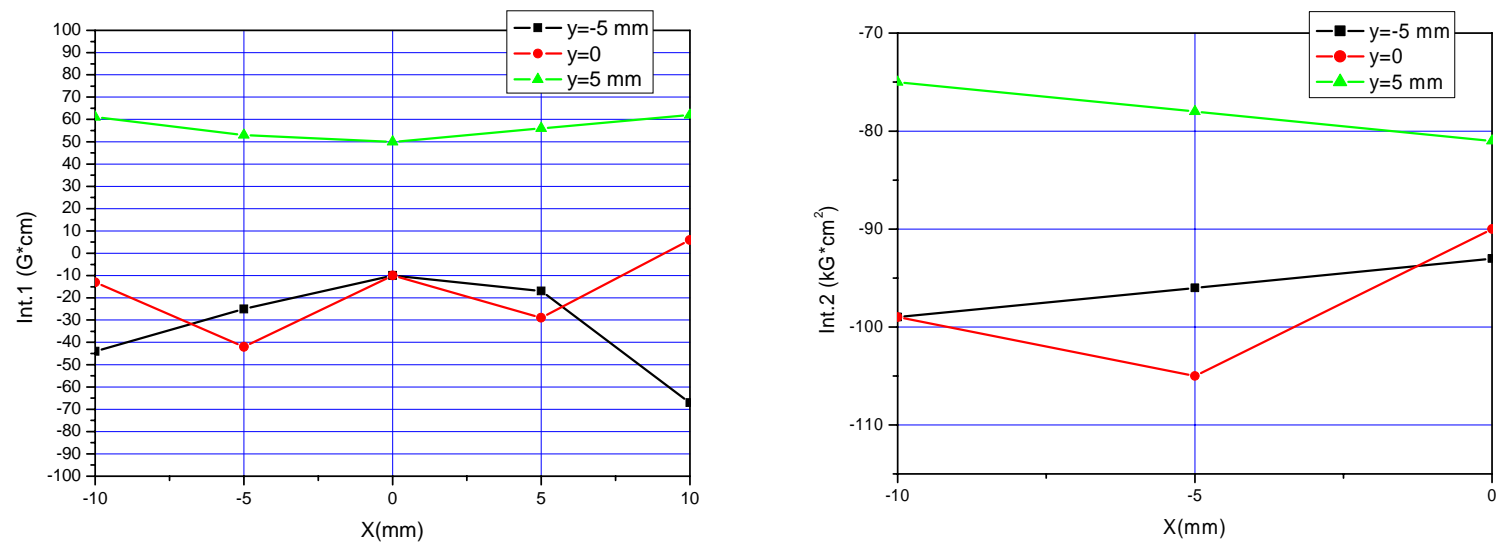

Figure 26 Field integrals at 123.2 A main coil excitation
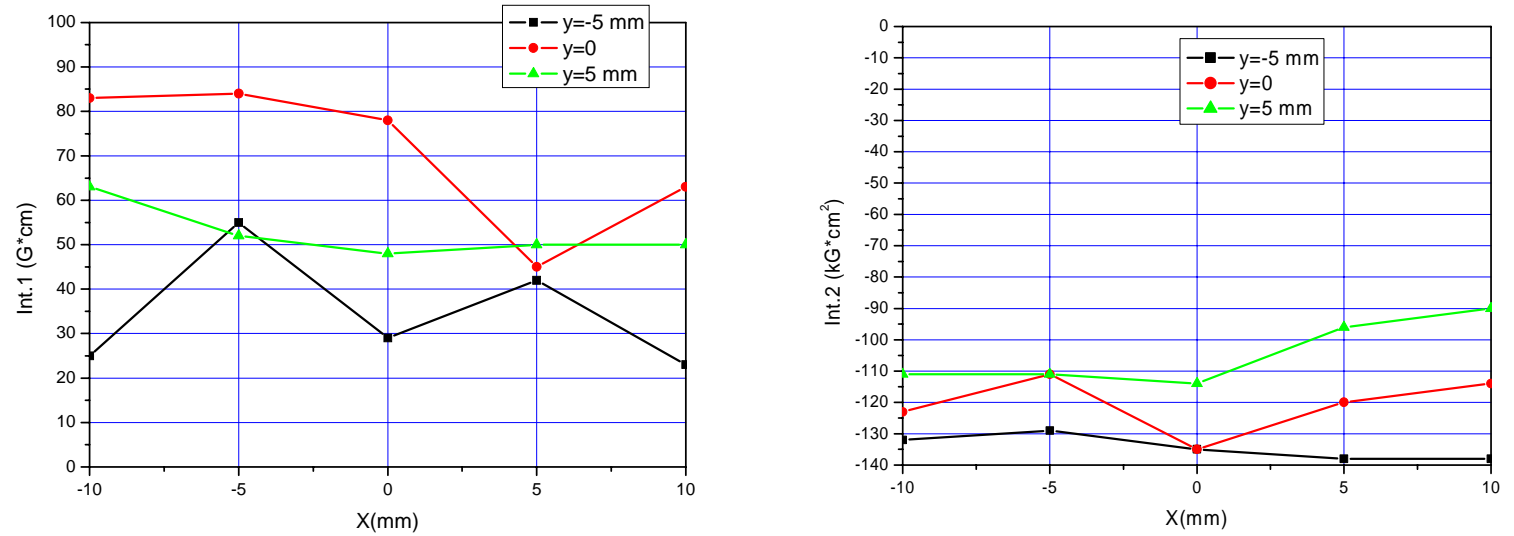

Figure 27 Field integrals at 200 A main coil excitation
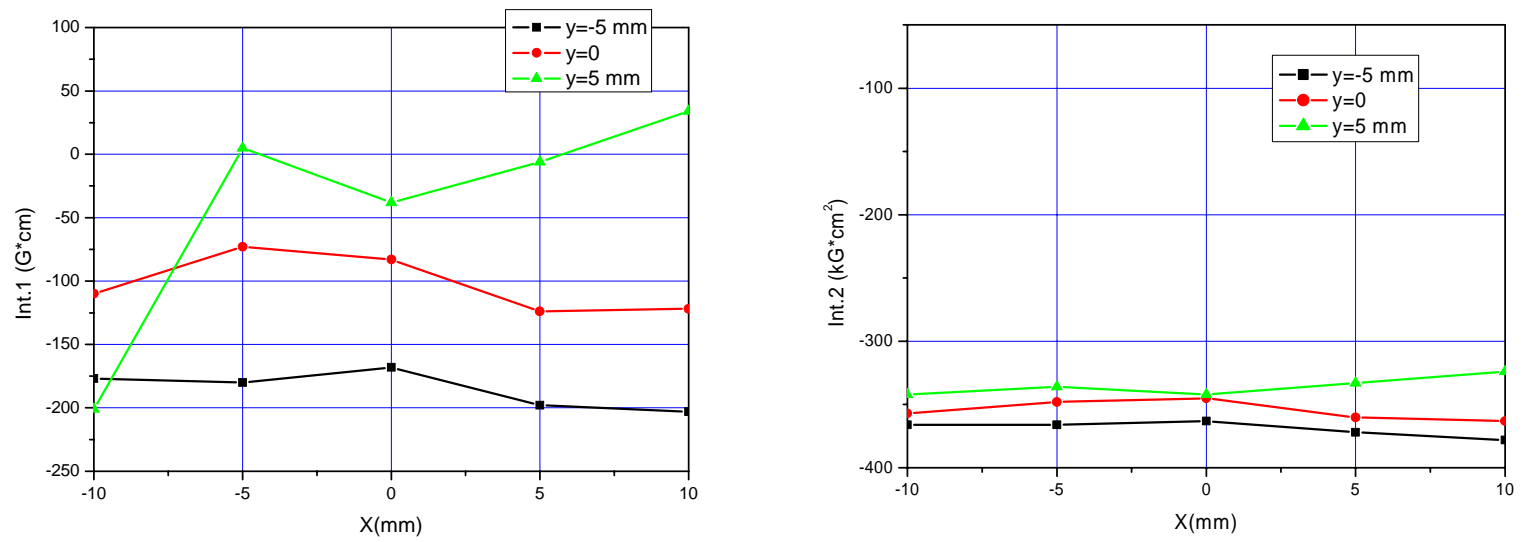

Figure 28 Field integrals at 300 A main coil excitation 

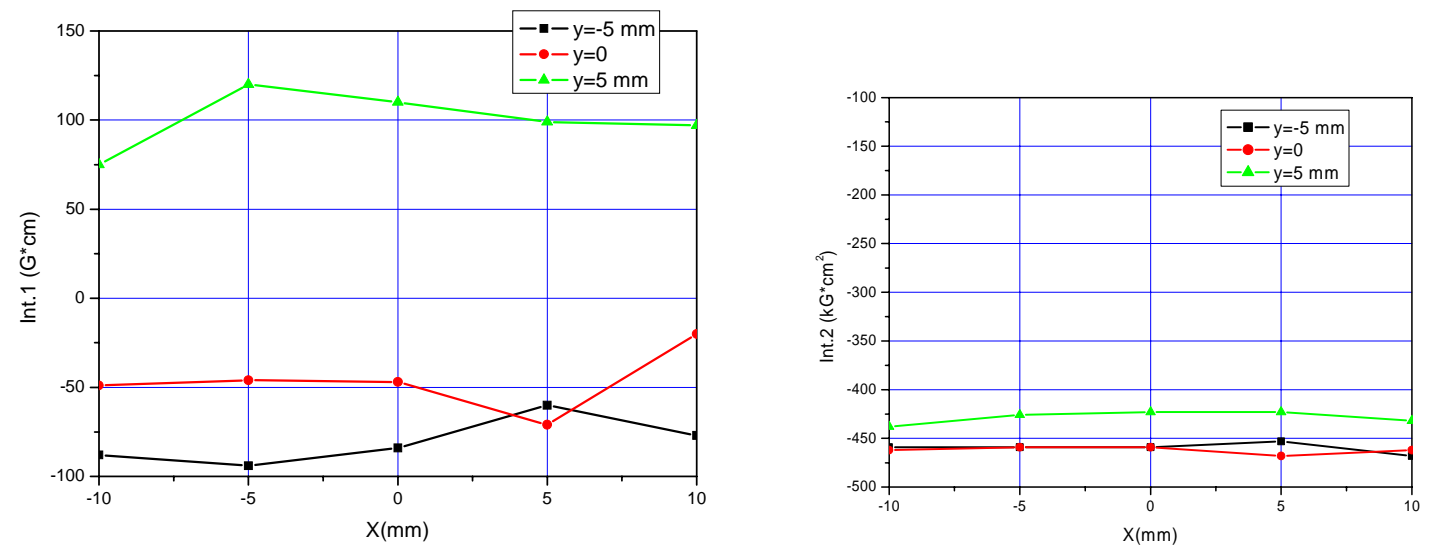

Figure 29 Field integrals at 340 A main coil excitation
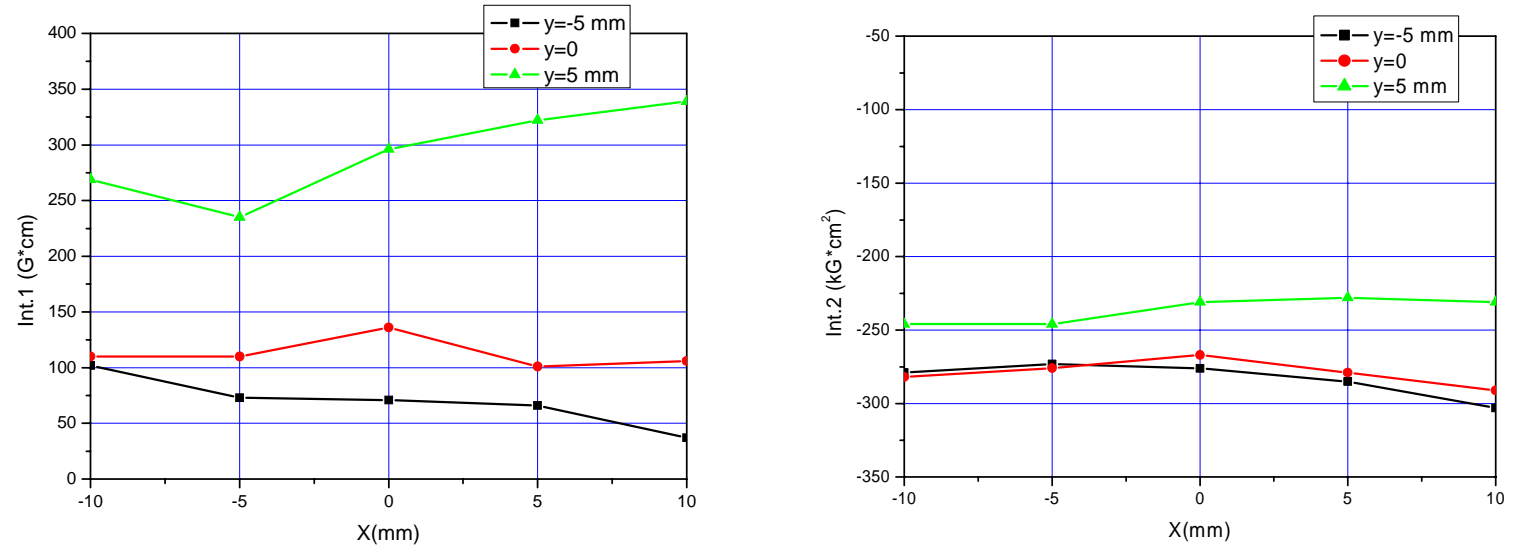

Figure 30 Field integrals at 435 A main coil excitation

\subsection{Transverse field distributions}

The results of the measurements of the undulator magnetic field in transverse direction for five pole pairs and three excitation currents are presented in Figure 31 - Figure 33 and compared for an excitation of 200 A in Figure 34. 

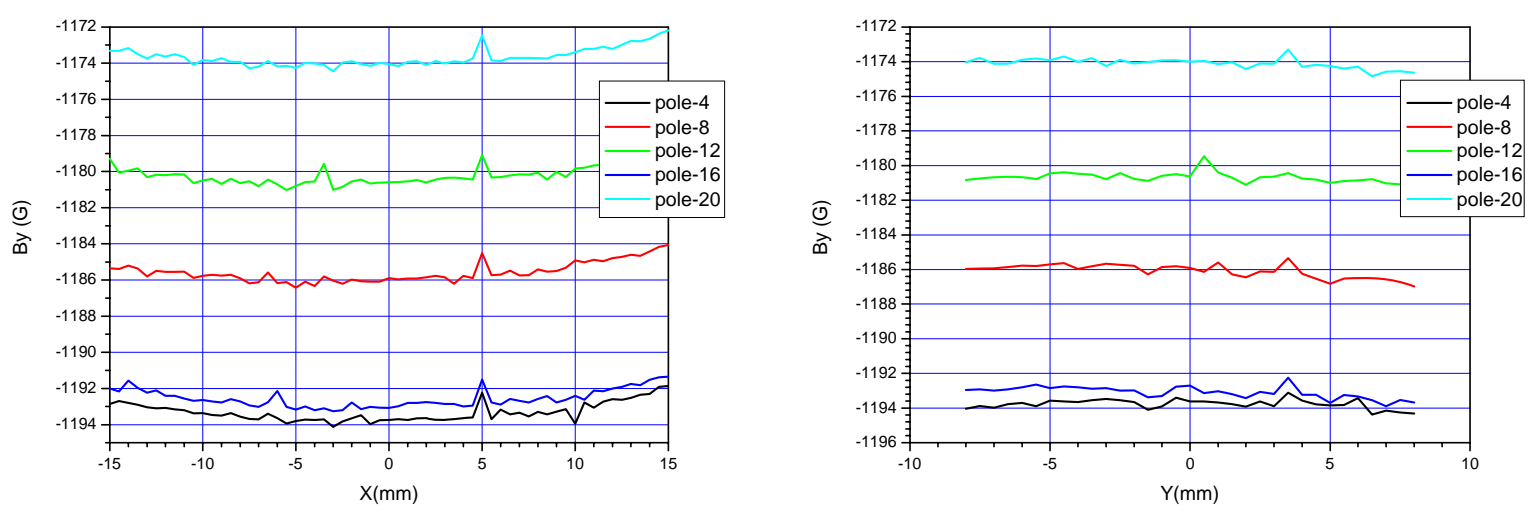

Figure 31 Horizontal and vertical field profiles at $30 \mathrm{~A}$
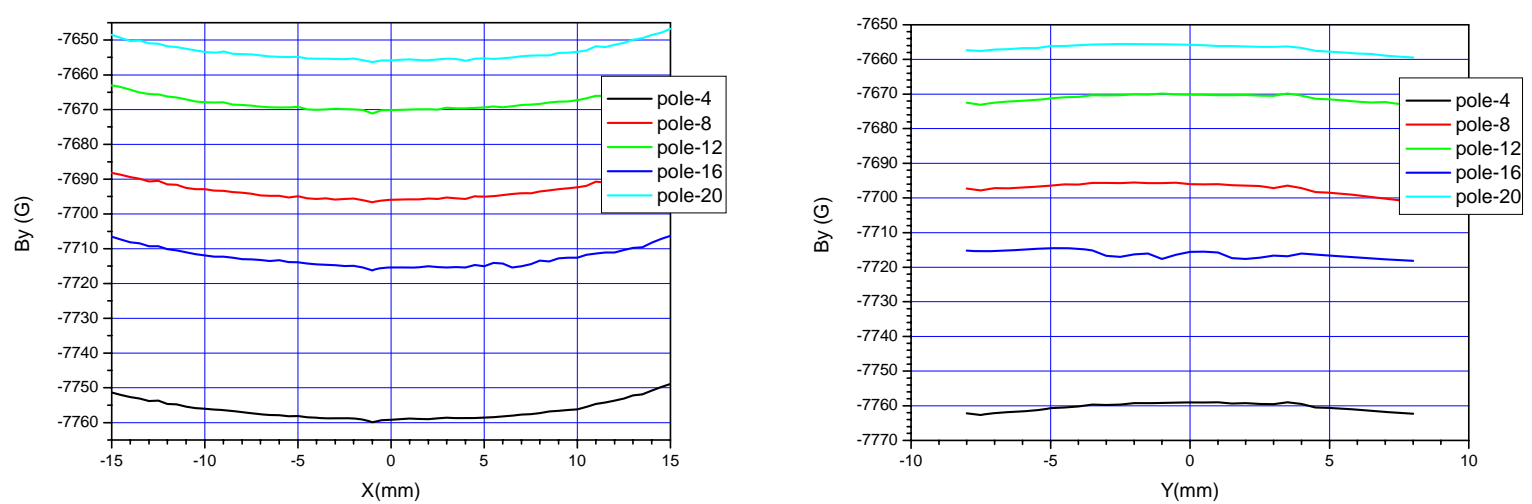

Figure 32 Horizontal and vertical field profiles at $200 \mathrm{~A}$
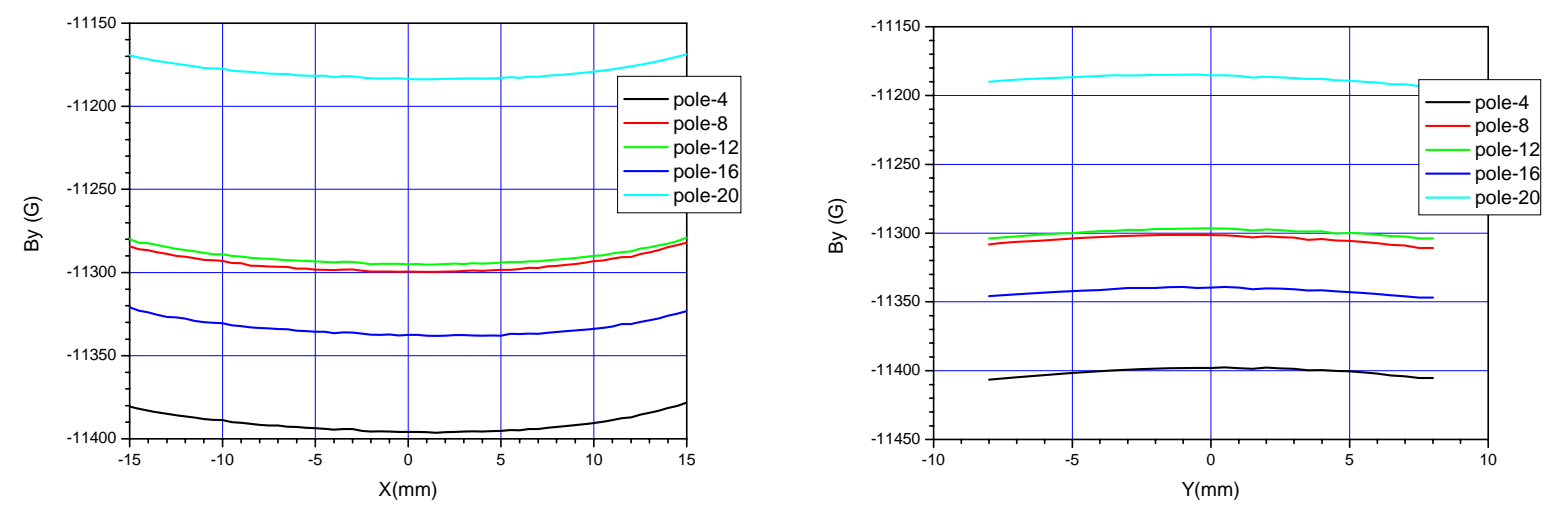

Figure 33 Horizontal and vertical field profiles at 435 A 

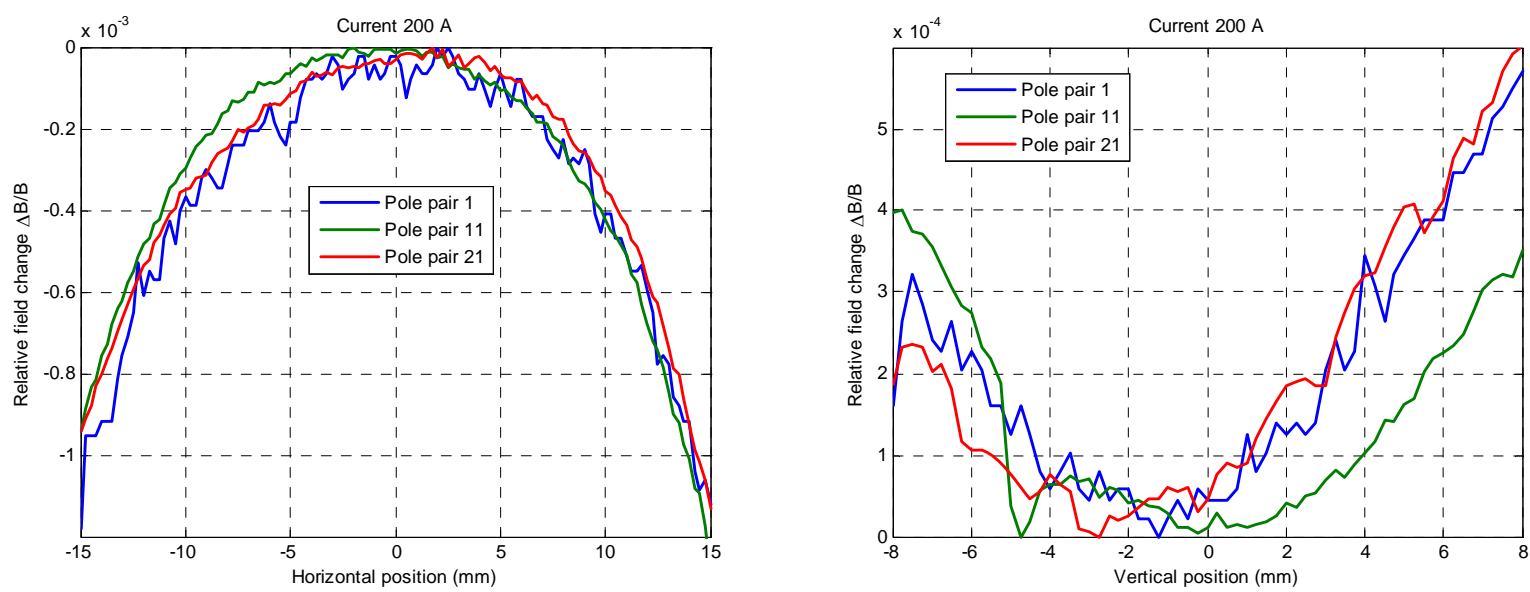

Figure 34 Transverse field profiles at 200 A excitation current

\subsection{Temperature transients}

The undulator consumes up to $110 \mathrm{~kW}$ electrical power at maximum excitation (252 V at $435 \mathrm{~A}$ ). Operation will require frequent changes in the excitation current, therefore the time scales for transients, especially on the magnetic field integrals, is needed.

Figure 35 shows the rise and fall of the water temperature with time when ramping the current from 0 to $415 \mathrm{~A}$ (100 kW power) and back. Ramping of the power supply takes about 4 minutes. Time zero in the figure is not exactly coinciding with the start of the ramp. Within about 10 minutes, the water temperature has reached equilibrium. There is no further rise noticeable even when running for 24 hours. As the coils are in direct contact with the water, they also will have reached equilibrium after 10 minutes. The measured magnetic field itself does still change over a period of about 6 hours, as seen in Figure 36. The Hall probe was positioned centrally in pole pair 17, and the undulator powered with 435 A main coil current.

Both power supply and Hall probe have an accuracy of about $10^{-4}$, consistent with the small fluctuations after 6 hours. The initial decrease of the field of the order of $5 \times 10^{-4}$ is likely due to temperature effects of the undulator. A contribution from the power supply cannot be excluded, but it has significantly less thermal mass to provide such a long time constant. The Hall probe has a temperature coefficient of $1 \times 10^{-5} / \mathrm{K}$ and a zero drift of $\pm 1 \mu \mathrm{T} / \mathrm{K}$ and, as the air in the open gap of the undulator cannot be heated significantly, will not contribute to this drift. 


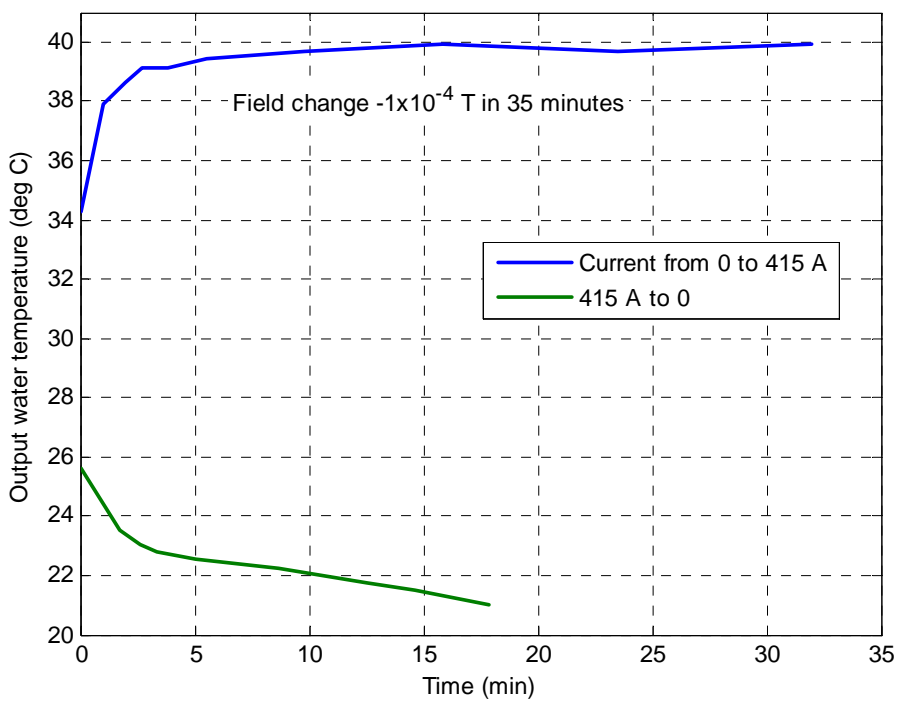

Figure 35 Change of water output temperature with time

To investigate temperature effects of the undulator, a Fluke Ti45 thermography camera was used $^{5}$. As temperature changes are of concern here, and not absolute values, the emissivity value was left fixed at 0.95 (this value gives correct absolute temperatures for example for the rubber water pipes of the undulator). Figure 37 shows an example of such thermographic images. From a series of such measurement, the outside of the coils are found to be in equilibrium after about 30 minutes. The coils themselves are in good contact with the water, but the epoxy glue around them has bad heat conductivity, resulting in a longer time scale than the water itself.

The thermal coupling of the coils to the massive iron yoke and the support structure is weak and explains the 6 hour time constant found for the magnetic field.

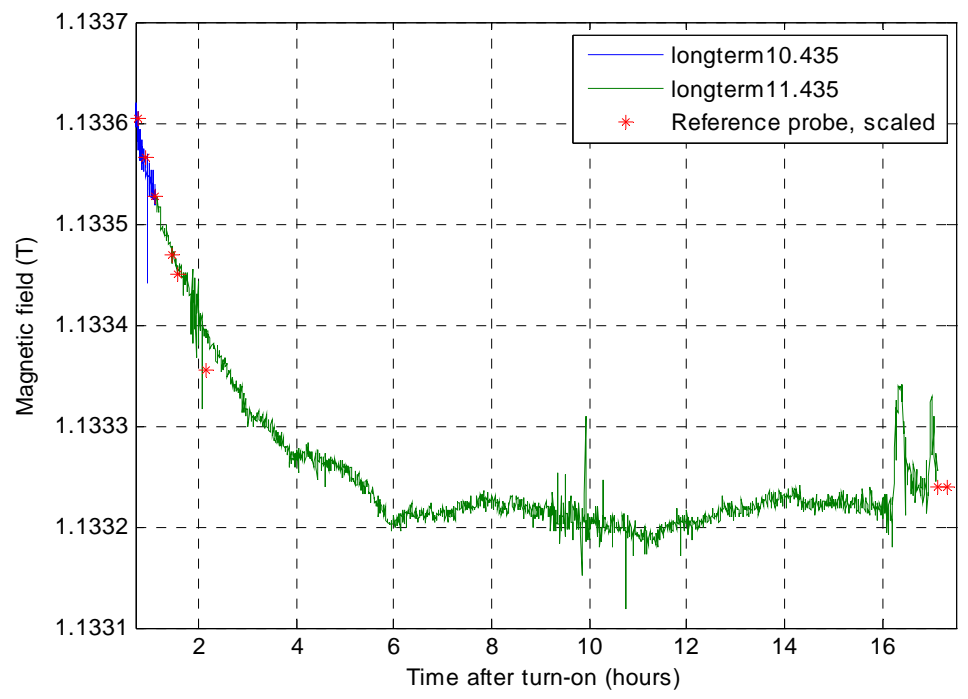

Figure 36 Magnetic field change at pole pair 17 at 435 A current.

\footnotetext{
${ }^{5}$ The camera has been provided and operated by H. Hirsemann, MEA2.
} 
In Figure 38, thermographic images show details of the yoke and the support structure and how they heat up over a longer time. They were taken at the beginning and end of the long-term measurement of Figure 36.
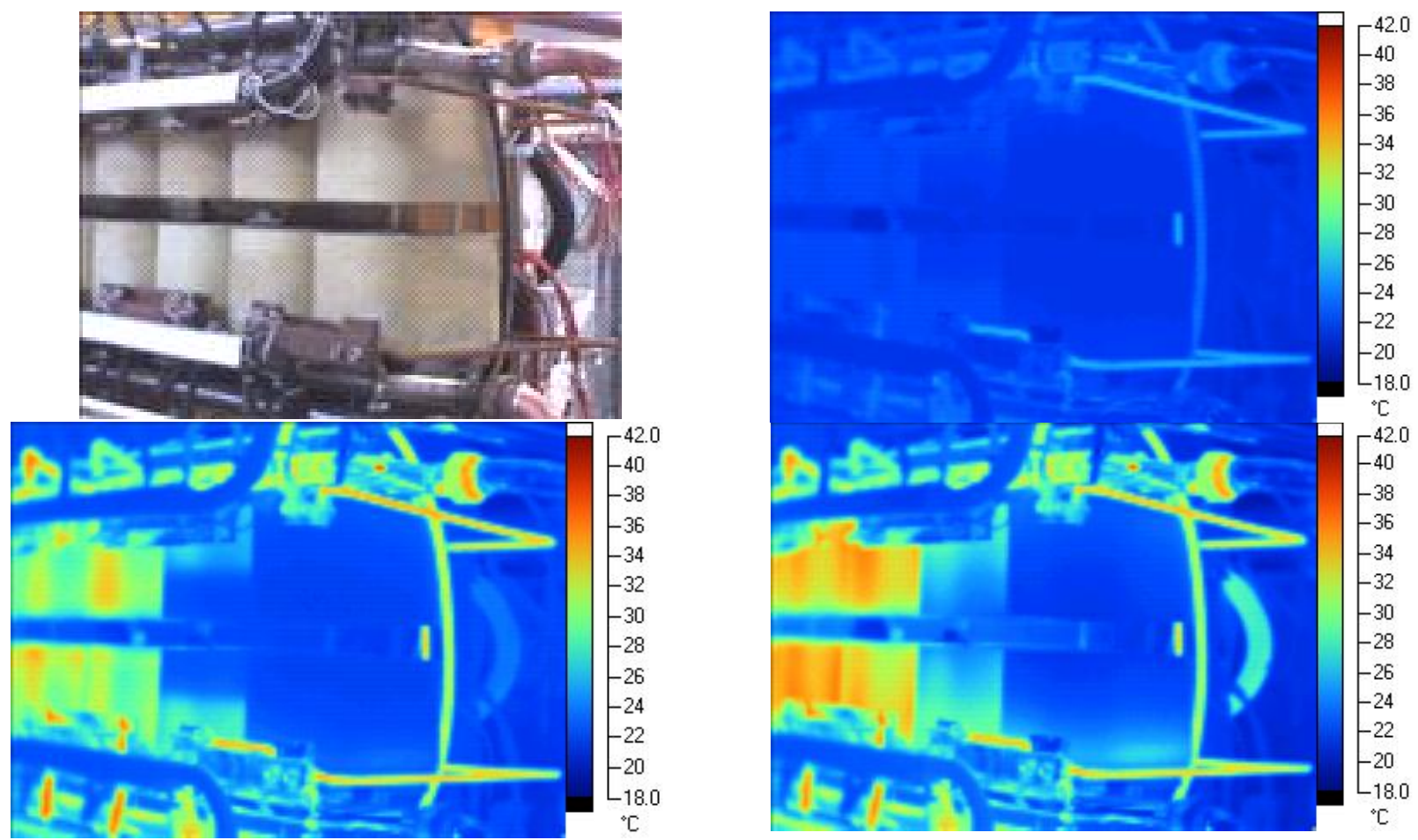

Figure 37 Thermographic images before switching on with $435 \mathrm{~A}, 10$ minutes later and 60 minutes later (clockwise). Emissivity 0.95 . 

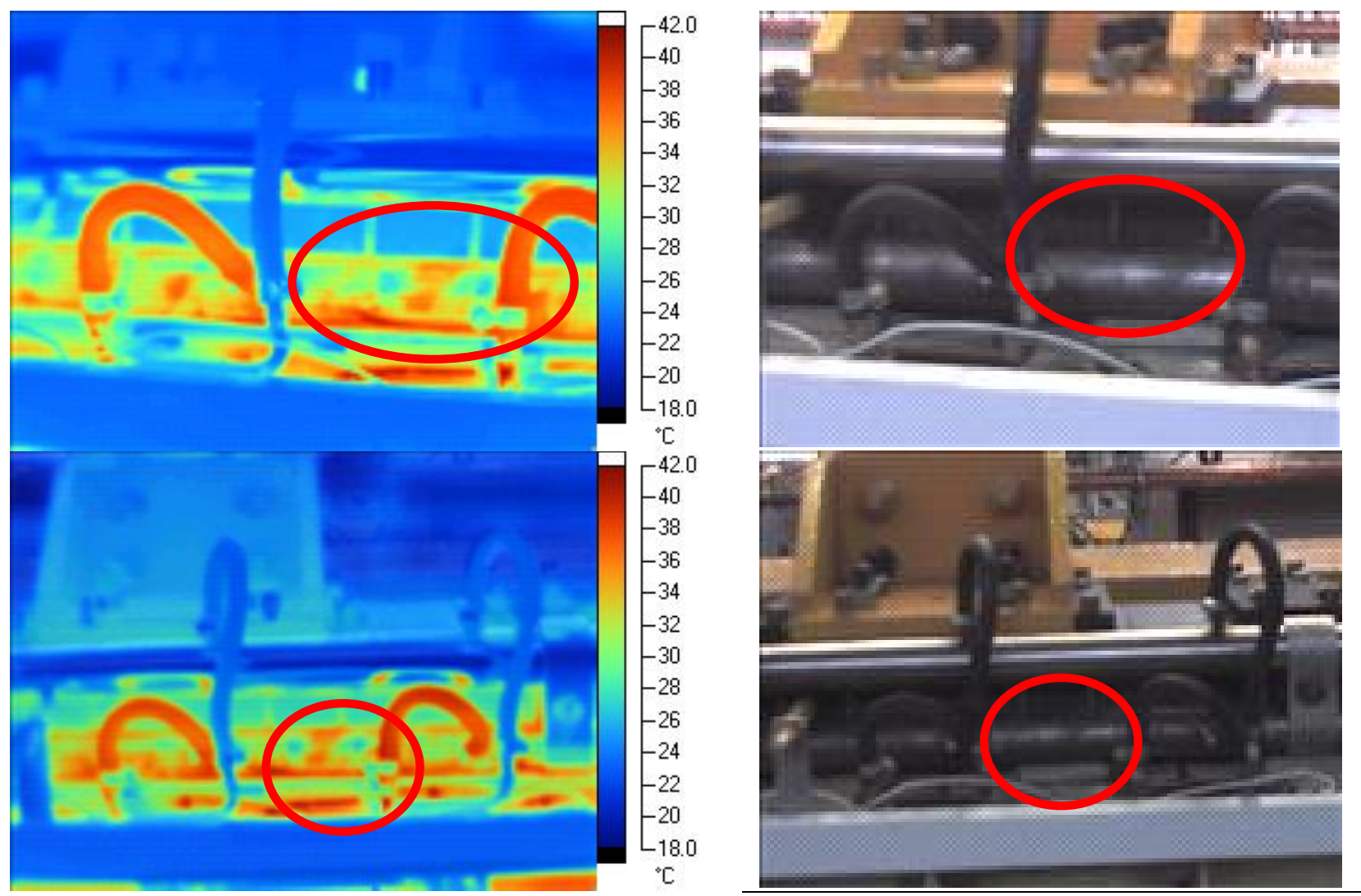

Figure 38 Thermogaphic images 1 hour and 17 hours after switching on with 435 A.

Due to the special winding of the end coils, peculiar heating and cooling patterns can be observed, an example of which is shown in Figure 39. Only the part of the epoxy glue that has copper windings underneath is cooled relatively quickly after switching off the current.

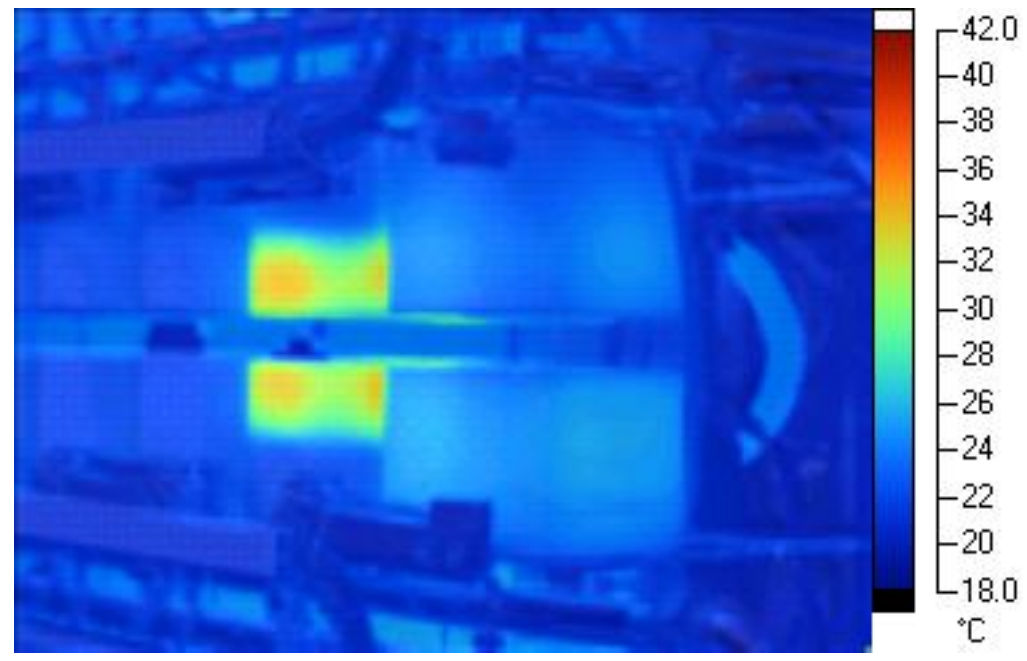

Figure 39 Thermographic image 30 minutes after switching off, following an overnight running at 435 A. 
The long-term undulator magnetic field-integral variation was studied during a 27 hour run at maximum excitation current of $435 \mathrm{~A}$. Each hour during the day magnetic field measurements were done. The results are shown in Figure 40. Although the magnetic field itself changes over a period of several hours, the field integrals are immediately stable. This finding can be attributed to thermal expansion of the yoke: the field changes due to gap changes, but the field integral is compensated by a similar longitudinal expansion.

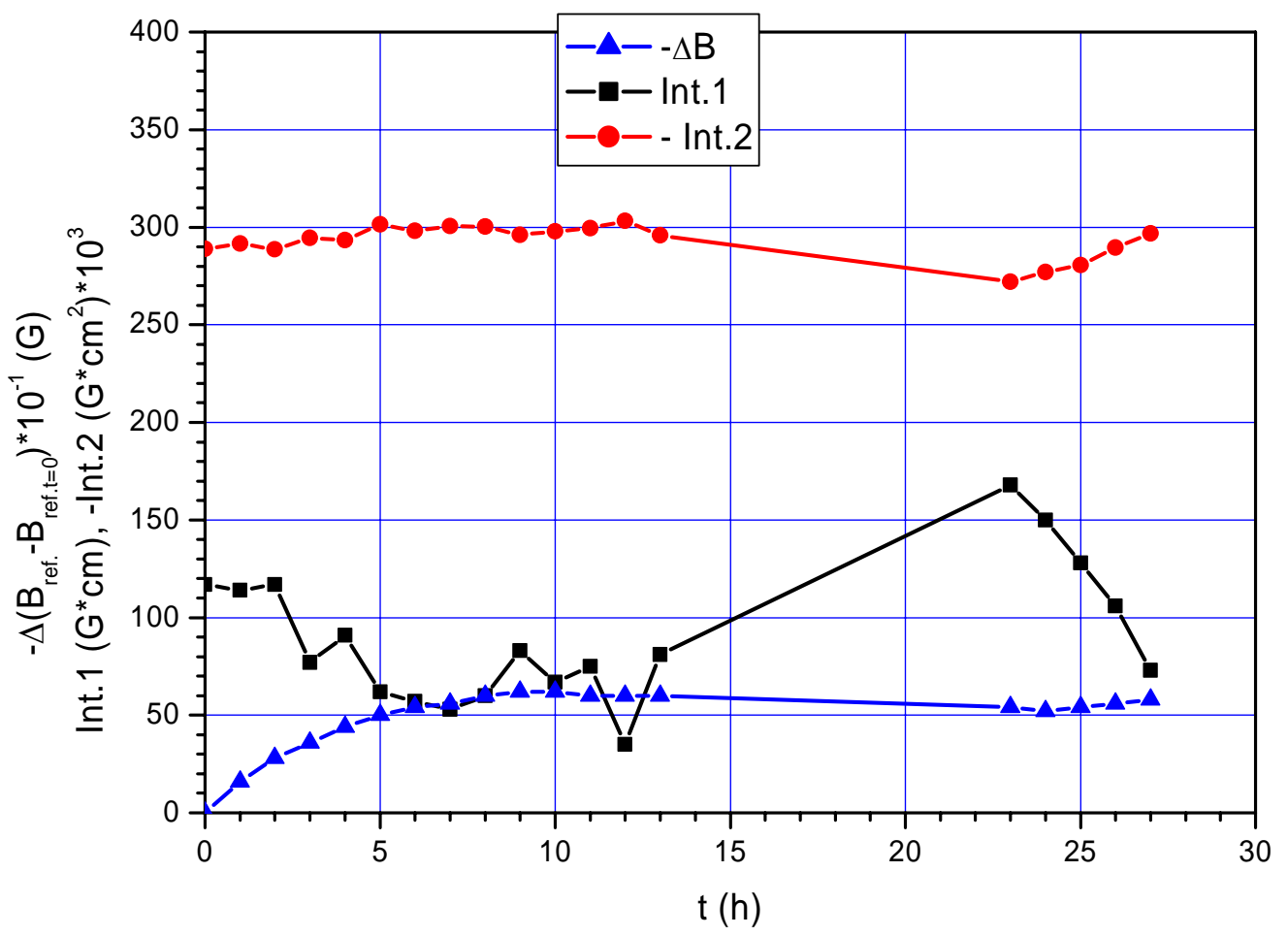

Figure 40 Data for the long test run of the undulator 


\section{Undulator operation}

This section summarizes the results from the magnetic tuning that are relevant for actual operation of the undulator. It does not contain information about the operation within the context of the FLASH accelerator, as this will require machine specific settings that will be determined only during dedicated commissioning shifts and will be reported separately.

\subsection{Corrector coil settings}

The basic result of the undulator tuning is the determination of correct corrector coil settings for all main coil excitations. These settings are listed in Table 2, together with the measured first and second field integral over the undulator length (integrals determined over $5 \mathrm{~m}$ ). The file name refers to the data file that contains the actual longitudinal magnetic field profile as obtained with the Hall probe. The currents are also graphically shown in Figure 41.

Table 2 Parameters for the basic undulator set points

\begin{tabular}{|c|c|c|c|c|c|c|c|c|c|c|}
\hline $\begin{array}{c}\mathbf{I}_{\text {main }} \\
(\mathrm{A})\end{array}$ & $\begin{array}{c}\text { File } \\
\text { name }\end{array}$ & $\begin{array}{c}\text { P12 } \\
\text { left(A) }\end{array}$ & $\begin{array}{c}\text { P3 } \\
\text { right(A) }\end{array}$ & $\begin{array}{c}\text { P1 } \\
(\mathrm{A})\end{array}$ & $\begin{array}{c}\text { P22 } \\
(\mathrm{A})\end{array}$ & $\begin{array}{c}\text { P2 } \\
(\mathrm{A})\end{array}$ & $\begin{array}{c}\mathbf{P 2 1} \\
(\mathrm{A})\end{array}$ & $\begin{array}{c}\text { Int.1 } \\
(\mathrm{G} \cdot \mathrm{cm})\end{array}$ & $\begin{array}{c}\text { Int.2 } \\
\left(\mathrm{kG} \cdot \mathrm{cm}^{2}\right)\end{array}$ & $\mathbf{K}$ \\
\hline 0 & $\mathrm{D}-402$ & 0 & 0 & 0.53 & 0.7 & 0 & 0 & 23 & -18 & 0.356 \\
\hline 2 & $\mathrm{D}-403$ & -0.01 & -0.45 & 0.0 & 0.18 & 0.12 & -0.18 & -63 & -10.5 & 0.455 \\
\hline 5 & $\mathrm{D}-404$ & -0.03 & -0.4 & -0.05 & 0.45 & 0.29 & -0.46 & -12 & -8.1 & 0.846 \\
\hline 12 & $\mathrm{D}-406$ & -0.072 & -0.45 & -0.30 & 1.08 & 0.68 & -1.1 & -88 & 12.9 & 1.88 \\
\hline 20 & $\mathrm{D}-411$ & -0.12 & -0.134 & -0.27 & 1.3 & 1.14 & -1.07 & -34 & -1.5 & 3.08 \\
\hline 30 & $\mathrm{D}-414$ & -0.18 & -0.2 & -0.7 & 1.65 & 1.7 & -1.6 & -47 & -3.9 & 4.58 \\
\hline 50 & $\mathrm{D}-417$ & -0.3 & -0.32 & -1.0 & 1.95 & 2.4 & -2.4 & -58 & 8.7 & 7.63 \\
\hline 78 & $\mathrm{D}-419$ & -0.4 & -0.43 & -1.4 & 2 & 3.4 & -3.1 & -129 & -69 & 11.9 \\
\hline 90 & $\mathrm{D}-422$ & -0.5 & -0.5 & -1.6 & 2.1 & 4 & -3.7 & -73 & -129 & 13.7 \\
\hline 123.2 & $\mathrm{D}-424$ & -0.67 & -0.67 & -2.6 & 3.1 & 5.4 & -5.2 & -86 & -126 & 18.8 \\
\hline 170 & $\mathrm{D}-437$ & -0.9 & -0.9 & -2.7 & 3.0 & 6 & -5.7 & -81 & -122 & 25.8 \\
\hline 200 & $\mathrm{D}-440$ & -1 & -1 & -3.2 & 3.8 & 6.3 & -6 & -52 & -183 & 29.6 \\
\hline 230 & $\mathrm{D}-442$ & -1.1 & -1.1 & -2.1 & 3.2 & 4.6 & -4.6 & -52 & -122 & 32.7 \\
\hline 260 & $\mathrm{D}-444$ & -1.2 & -1.2 & -1.7 & 3.0 & 3 & -3.1 & 23 & -249 & 35.2 \\
\hline 275 & $\mathrm{D}-446$ & -1.2 & -1.2 & -1.5 & 3.1 & 2.1 & -2.4 & 52 & -141 & 36.2 \\
\hline 300 & $\mathrm{D}-447$ & -1.1 & -1.1 & -0.5 & 2.6 & 0.1 & -0.3 & -151 & -354 & 37.9 \\
\hline 332.7 & $\mathrm{D}-449$ & -1 & -1 & 0.55 & 1.5 & -2.5 & 2.6 & -58 & -405 & 39.6 \\
\hline 340 & $\mathrm{D}-450$ & -1 & -1 & 1.2 & 1.2 & -3.4 & 3.3 & -146 & -462 & 39.9 \\
\hline 380 & $\mathrm{D}-451$ & -1.5 & -1.2 & 2.7 & 0 & -7 & 6.8 & -49 & -381 & 41.6 \\
\hline 390 & $\mathrm{D}-453$ & -1.6 & -1.2 & 3.2 & -0.6 & -8 & 7.8 & 94 & -378 & 41.9 \\
\hline 420 & $\mathrm{D}-455$ & -1.6 & -1.2 & 2.8 & 0.4 & -8.4 & 7.8 & -46 & -345 & 42.0 \\
\hline 435 & $\mathrm{D}-457$ & -1.6 & -1.2 & 2.5 & 0.7 & -8.4 & 7.8 & 10 & -321 & 43.5 \\
\hline
\end{tabular}


The $\mathrm{K}$ value is calculated from the first harmonic wavelength that was obtained from numerical simulation of the on-axis spectrum according to $\lambda=\frac{\lambda}{2 \gamma^{2}}\left(1+\frac{K^{2}}{2}\right)$.

Corrector settings for main excitations at other values are obtained by linear interpolation. The full corrector listing in steps of 1 A main coil excitation is given in Appendix C.

The power supply designation in the FLASH control system is U6EXP for the main power supply, and U6PxEXP for the six correctors, where $\mathrm{x}$ designates the pole pair or first pole pair on which the respective power supply acts.

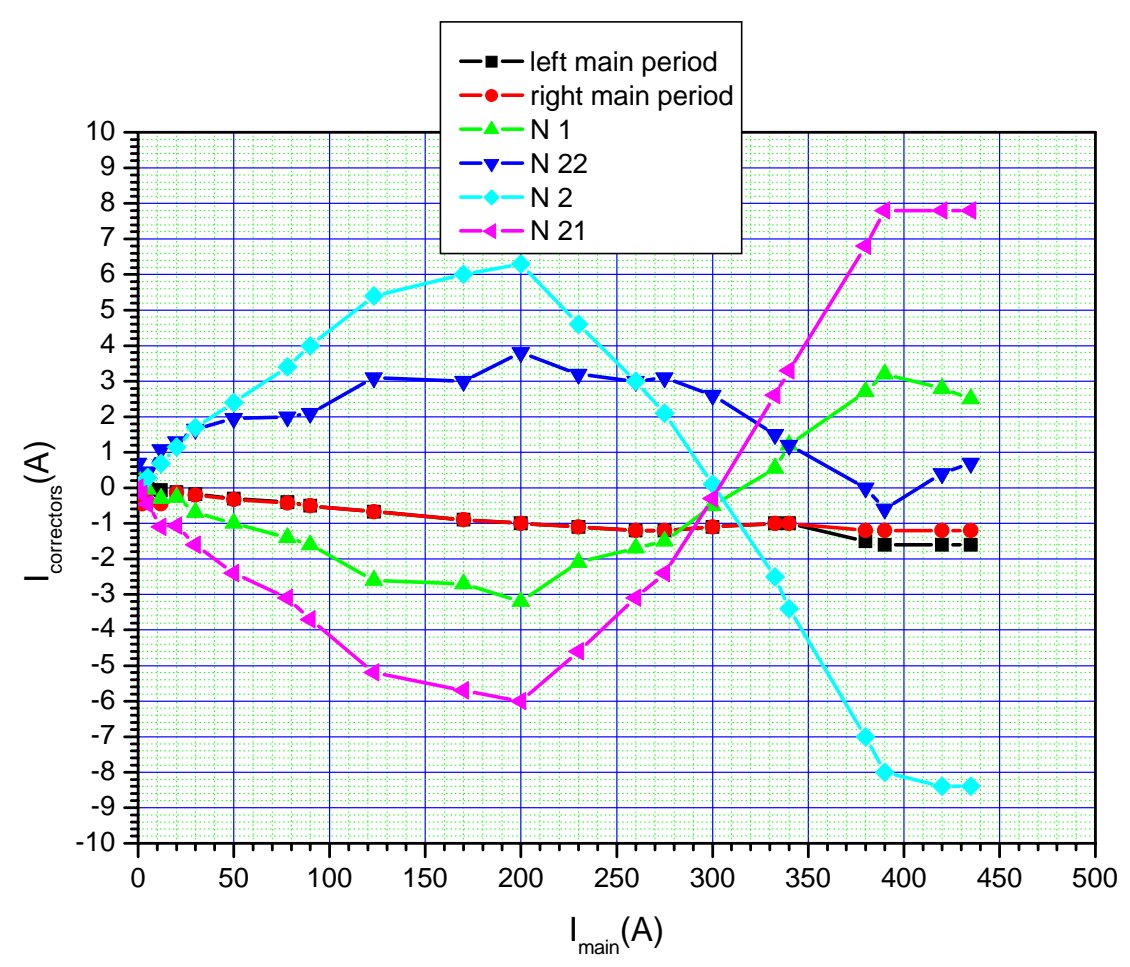

Figure 41 Corrector coil settings

\subsection{Procedure for regime change, cycling procedure}

An important goal of the magnetic measurements was to achieve good reproducibility of the undulator tuning with respect to the field integrals. The cycling procedure of the undulator to give well defined initial conditions consists of exciting the main coil with $0 \mathrm{~A}$, then $435 \mathrm{~A}$, then $0 \mathrm{~A}$ again. All correctors should be at 0 A (or off). The coils are then set to the desired value in the following order:
1. Main coils
5. U6P22EXP
2. U6P12EXP (left)
6. U6P2EXP
3. U6P3EXP (right)
7. U6P21EXP
4. U6P1EXP 
To change the main coil excitation, first set the correction coil currents to zero in the opposite order. If the new main coil excitation is higher than the current, set the new value directly. If it is lower, first go to $435 \mathrm{~A}$, then to $0 \mathrm{~A}$, then to the new target value. The corrector are then switched on in the order given above.

Results on the reproducibility of first and second field integral are shown Figure 42 and Figure 43.

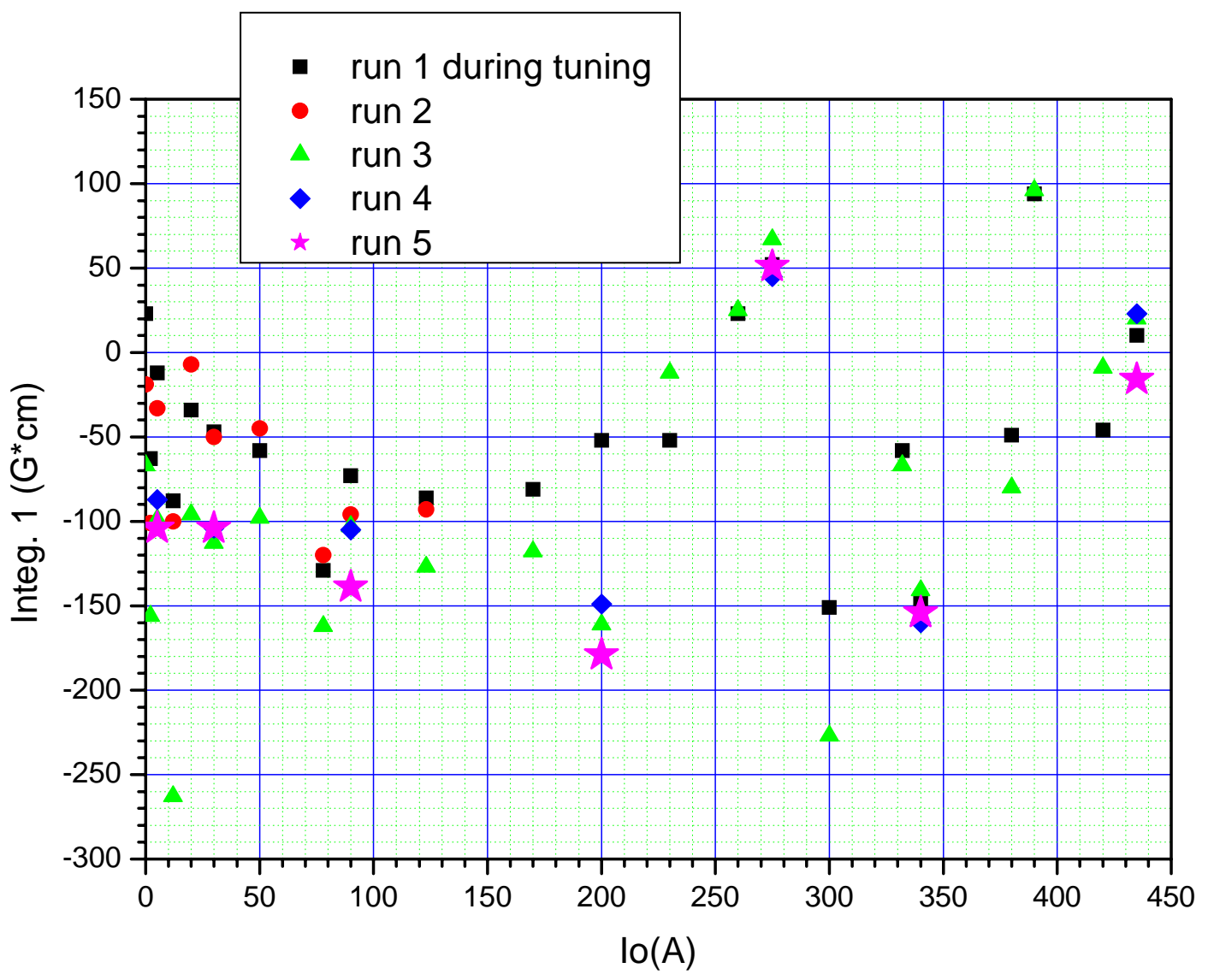

Figure 42 Reproducibility of first field integral 


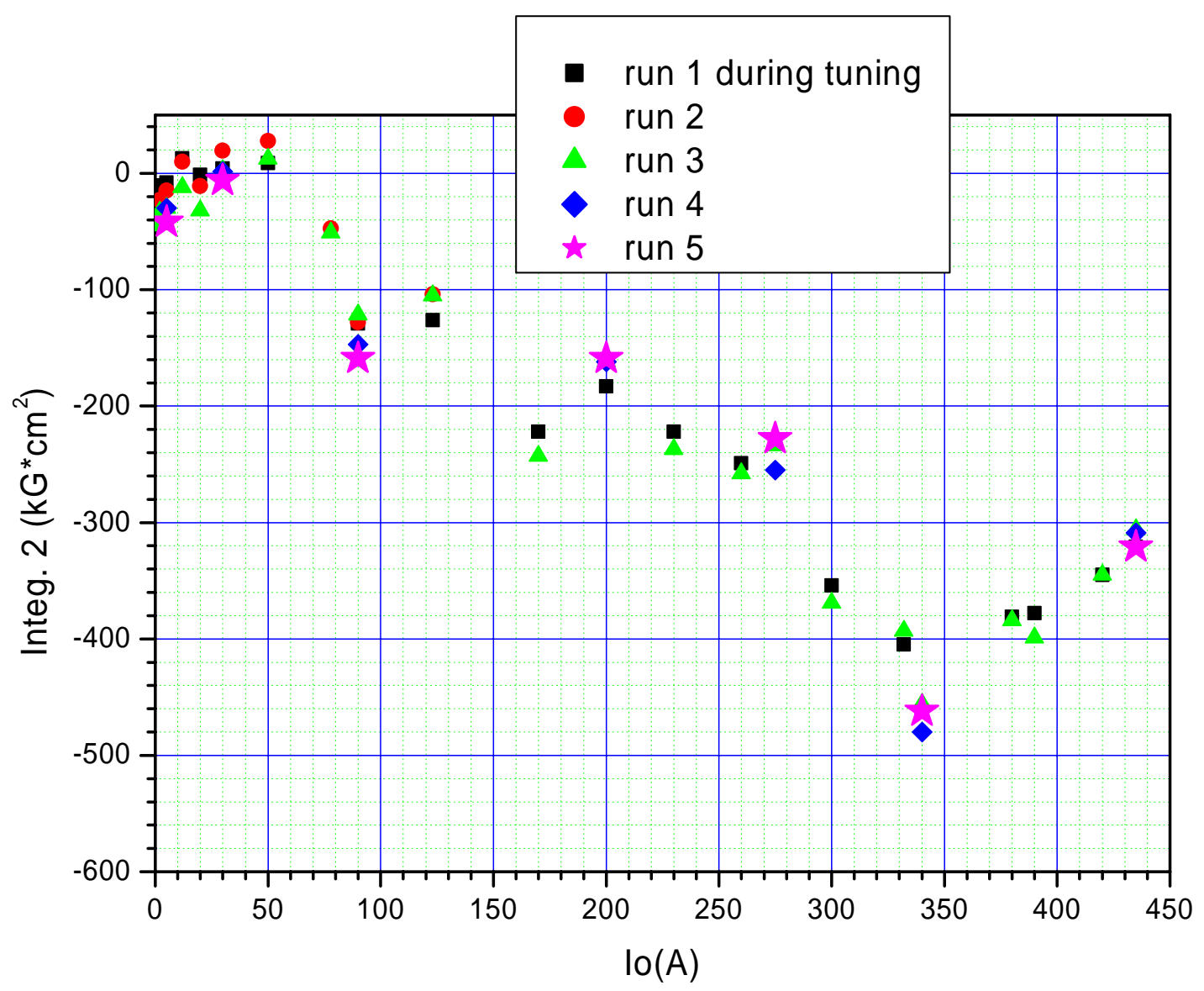

Figure 43 Reproducibility of second field integral

\subsection{Degaussing procedure}

The objective of the degaussing procedure is to minimize the remnant magnetic field. The excitation main coil current in Amps for the degaussing procedure are as follows (moving from one current to the next at the slew rate of the power supply):

$+400,-400,+200,-100,+50,-40,+30,-20,+15,-13,+11,-9,+7,-5,+4,-3,+2,-1,+0.5,-0.25,0$

The distribution of the remnant magnetic field before and after degaussing is shown in Figure 44. The maximum value of the remnant field was decreased to about $3 \mathrm{G}$, though the second field integral has approximately the same behavior as before degaussing (Figure 45) due to the remaining DC field component. 


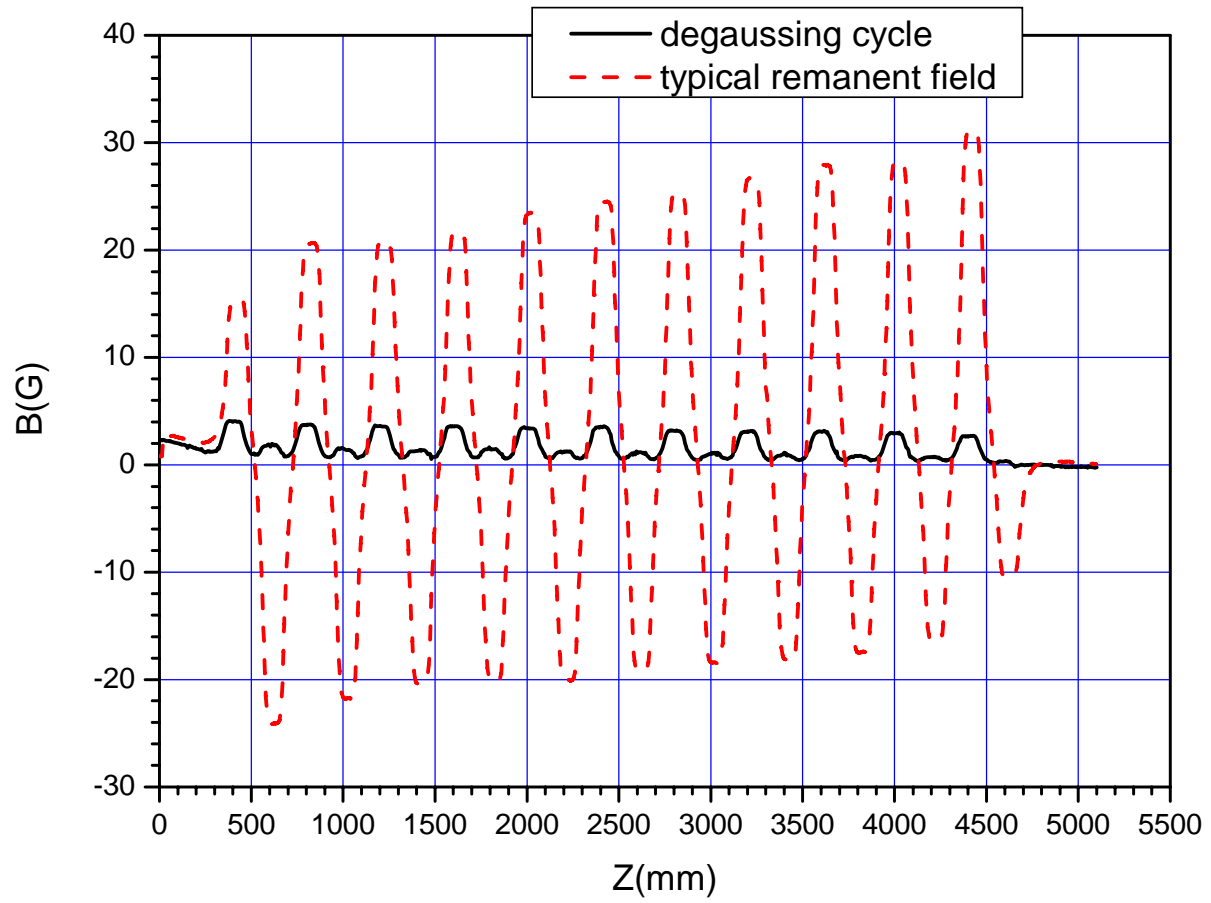

Figure 44 Typical remnant magnetic field and the field after degaussing cycle

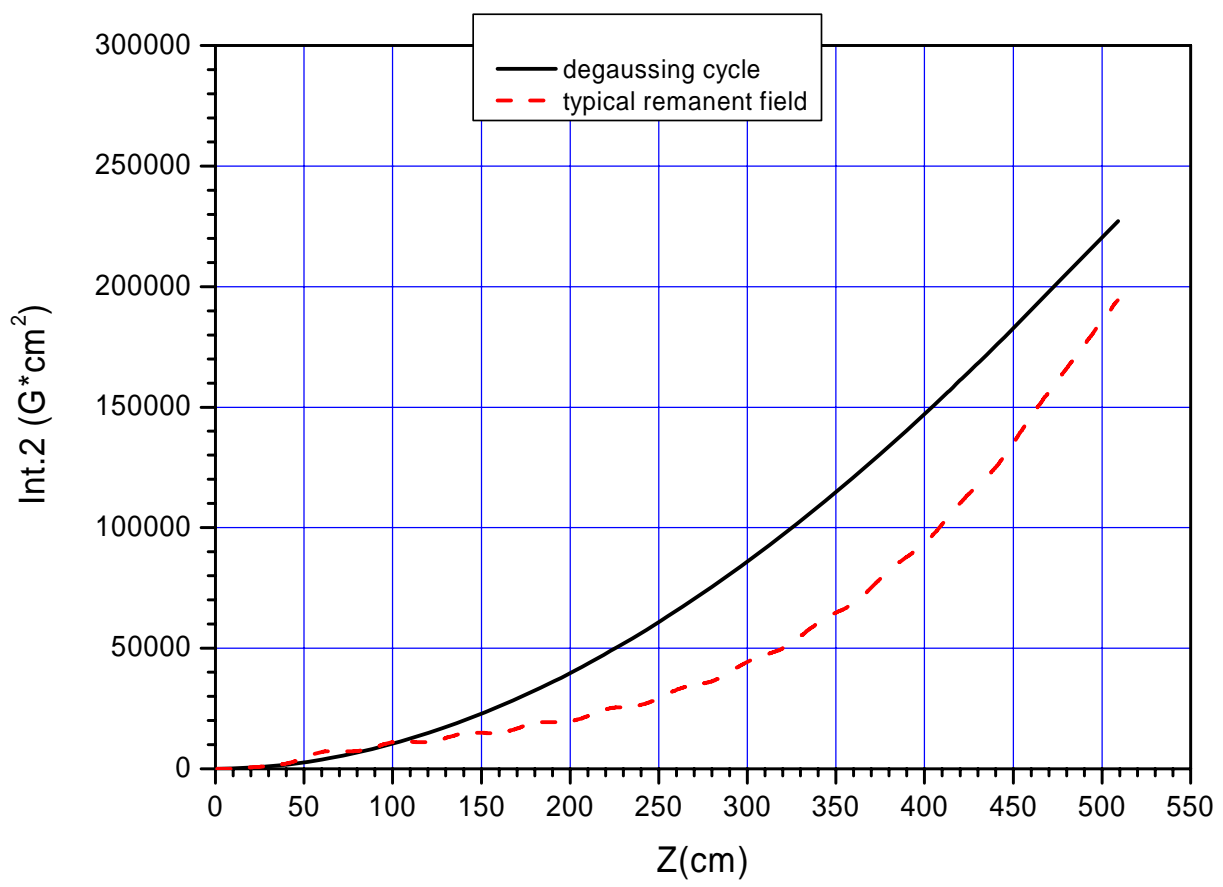

Figure 45 Second field integral of the remnant field before and after degaussing 


\section{A Referencing of tuning circuitry}

As the main coil correction coils are set via adjustable resistors and a number of switches at the back side of the undulator, referencing is necessary in case they are changed by accident or because a replacement of a broken part is necessary.

To this end, the current of the main coil correction coils (U6P3EXP and U6P12EXP) is set to $-1 \mathrm{~A}$, and the voltage measured the voltage between contacts N6 (ground) and N3 (signal). If necessary, the potentiometers should be adjusted to get the voltages listed below to better than $100 \mathrm{mV}$. The switch positions are given in brackets. The mail coil current should be at $200 \mathrm{~A}$. In small print are the results obtained just prior to installation of the undulator in the FLASH tunnel, both at 0 (left) and $200 \mathrm{~A}$ (right) main coil current.

\begin{tabular}{|c|c|c|c|c|c|}
\hline R1 & $\begin{array}{c}1.27 \mathrm{~V} \text { (up/down) } \\
1.28 / 1.28\end{array}$ & R7 & $\begin{array}{c}3.05 \mathrm{~V} \text { (up/down) } \\
3.06 / 3.08\end{array}$ & R13 & $\begin{array}{l}-2.1 \mathrm{~V} \text { (up/up) } \\
-2.06 /-2.07\end{array}$ \\
\hline R2 & $\begin{array}{c}1 \mathrm{~V} \text { (up/down) } \\
2.07 / 2.07\end{array}$ & $\mathrm{R} 8$ & $\begin{array}{c}0 \mathrm{~V} \text { (down/down) } \\
0.01 / 0.01\end{array}$ & $\mathrm{R} 14$ & $\begin{array}{r}-1.6 \mathrm{~V} \text { (up/up) } \\
-1.59 / \mathrm{n} / \mathrm{a}\end{array}$ \\
\hline R3 & $\begin{array}{c}2.1 \mathrm{~V} \text { (up/down) } \\
2.07 / 2.08\end{array}$ & R9 & $\begin{array}{l}-2.7 \mathrm{~V}(\mathrm{up} / \mathrm{up}) \\
-2.66 /-2.67\end{array}$ & $\mathrm{R} 15$ & $-5.9 \mathrm{~V}\left(\operatorname{up}_{-5.84 /-5.91}\right)$ \\
\hline $\mathrm{R} 4$ & $\begin{array}{c}2.53 \mathrm{~V} \text { (up/down) } \\
2.50 / 2.51\end{array}$ & $\mathrm{R} 10$ & $\begin{array}{c}0 \mathrm{~V}(\text { down/down }) \\
0.02 / 0.02\end{array}$ & R16 & $\begin{array}{r}-2.17 \mathrm{~V} \text { (up/up) } \\
-2.16 /-2.17\end{array}$ \\
\hline D & $\begin{array}{c}-0.59 \mathrm{~V}(\mathrm{up} / \mathrm{up}) \\
-0.58 /-0.58\end{array}$ & $\mathrm{R} 11$ & $\begin{array}{c}-3.48 \mathrm{~V}(\mathrm{up} / \mathrm{up}) \\
-3.39 /-3.41\end{array}$ & $\mathrm{R} 17$ & $\begin{array}{c}1.74 \mathrm{~V} \text { (up/down) } \\
1.72 / 1.73\end{array}$ \\
\hline & $\begin{array}{c}-0.51 \mathrm{~V} \text { (up/up) } \\
-0.54 /-0.54\end{array}$ & $\mathrm{R} 12$ & $\begin{array}{l}-4 \mathrm{~V} \text { (up/up) } \\
-3.93 /-3.96\end{array}$ & $\mathrm{R} 18$ & $\begin{array}{c}-0.93 \mathrm{~V} \text { (up/up) } \\
-0.93 /-0.93\end{array}$ \\
\hline
\end{tabular}

At $200 \mathrm{~A}$, the measured voltages are on average about $0.5 \%$ higher than at zero current, indicating a negligible influence of temperature on the referencing. 


\section{B Coils resistivities}

The voltage over each main coil was measured at 200 A excitation current, see Figure 46. They translate into resistances as follows:

\begin{tabular}{lccccccccccc} 
Pole \# & 1 & 2 & 3 & 4 & 5 & 6 & 7 & 8 & 9 & 10 & 11 \\
\hline $\mathrm{R}(\mathrm{m} \Omega)$ & 1.76 & 1.73 & 8.05 & 8.23 & 14.57 & 14.47 & 14.49 & 15.39 & 14.25 & 14.72 & 14.90 \\
& 12 & 13 & 14 & 15 & 16 & 17 & 18 & 19 & 20 & 21 & 22 \\
\cline { 2 - 10 } & 14.28 & 14.72 & 14.21 & 14.48 & 14.86 & 14.38 & 14.49 & 15.05 & 14.27 & 14.33 & 14.79 \\
& 23 & 24 & 25 & 26 & 27 & 28 & 29 & 30 & 31 & 32 & 33 \\
\cline { 2 - 10 } & 14.45 & 14.71 & 14.75 & 15.01 & 14.39 & 14.42 & 14.62 & 14.65 & 14.75 & 14.72 & 14.90 \\
& 34 & 35 & 36 & 37 & 38 & 39 & 40 & 41 & 42 & 43 & 44 \\
\cline { 2 - 10 } & 14.69 & 14.40 & 14.67 & 14.22 & 14.30 & 14.36 & 14.41 & 7.99 & 8.07 & 1.73 & 1.62
\end{tabular}

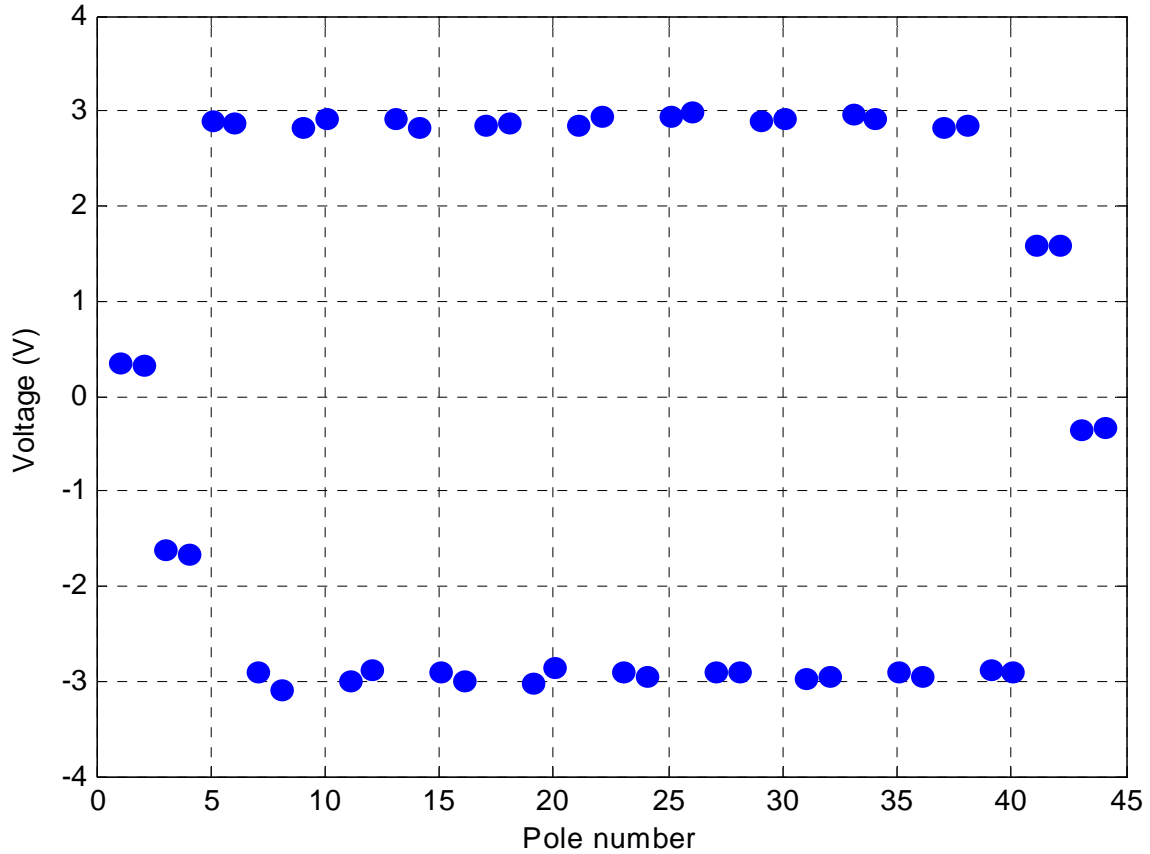

Figure 46 Voltage over all 44 coils at 200 A current

The edge corrector coil resistances have the following measured resistances (the deviation of sum from individual values indicates the measurement accuracy) :

\begin{tabular}{ccccccccccccc} 
Pole \# & 1 & 2 & 3 & 4 & 41 & 42 & 43 & 44 & $1+2$ & $3+4$ & $41+42$ & $43+44$ \\
\hline $\mathrm{R}(\Omega)$ & 0.52 & 0.55 & 0.55 & 0.56 & 0.55 & 0.53 & 0.55 & 0.52 & 1.06 & 1.05 & 1.11 & 1.07
\end{tabular}




\section{Magnetization data for pole-pair 11}

The magnetic field at the centre of pole pair 11 has been measured with high resolution as a function of main coil excitation. The correctors were set for each value as required by the tuning.

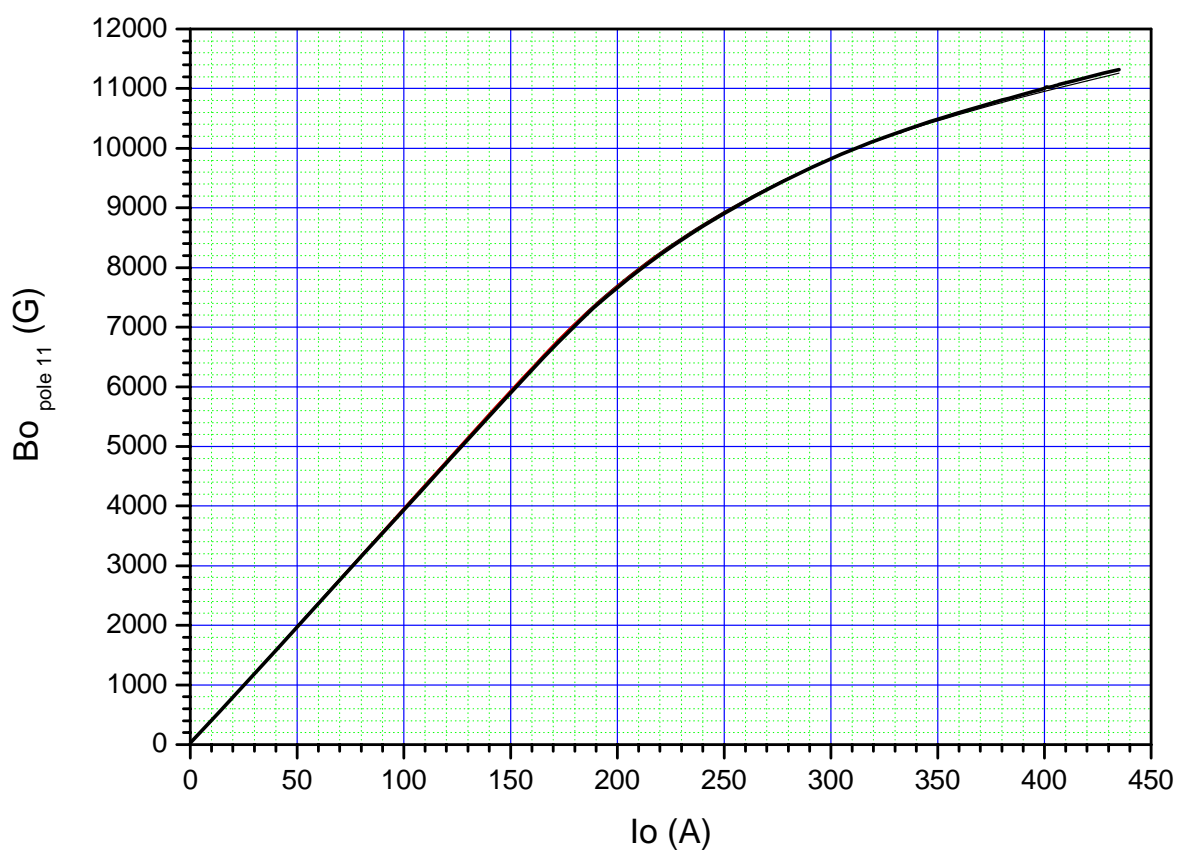

Figure 47 Magnetization curve for pole 11

\begin{tabular}{|c|c|}
\hline $\begin{array}{c}\text { Io } \\
(\mathbf{A})\end{array}$ & $\mathbf{B}(\mathbf{G})$ \\
\hline 0 & 26.34 \\
1 & 67.23 \\
2 & 107.41 \\
3 & 143.32 \\
4 & 180.51 \\
5 & 217.76 \\
6 & 256.02 \\
7 & 296.92 \\
8 & 335.43 \\
9 & 372.67 \\
10 & 411.54 \\
11 & 449.31 \\
12 & 487.54 \\
13 & 525.83 \\
14 & 566.4 \\
\hline
\end{tabular}

\begin{tabular}{|c|c|}
\hline 15 & 603.15 \\
16 & 641.59 \\
17 & 678.61 \\
18 & 717.66 \\
19 & 755.83 \\
20 & 794.09 \\
21 & 833.39 \\
22 & 872.26 \\
23 & 910.6 \\
24 & 950.01 \\
25 & 989.55 \\
26 & 1027.97 \\
27 & 1067.11 \\
28 & 1106.14 \\
29 & 1144.99 \\
30 & 1184.26 \\
31 & 1223.16 \\
\hline
\end{tabular}

\begin{tabular}{|c|c|}
\hline 32 & 1262.38 \\
33 & 1301.46 \\
34 & 1340.61 \\
35 & 1380.11 \\
36 & 1419.1 \\
37 & 1458.36 \\
38 & 1497.31 \\
39 & 1536.63 \\
40 & 1575.8 \\
41 & 1614.82 \\
42 & 1654.2 \\
43 & 1693.47 \\
44 & 1732.59 \\
45 & 1771.65 \\
46 & 1811.27 \\
47 & 1850.35 \\
48 & 1889.5 \\
\hline
\end{tabular}

\begin{tabular}{|c|c|}
\hline 49 & 1929.33 \\
50 & 1968.56 \\
51 & 2007.75 \\
52 & 2047.83 \\
53 & 2087.26 \\
54 & 2126.48 \\
55 & 2166.24 \\
56 & 2205.28 \\
57 & 2244.73 \\
58 & 2283.9 \\
59 & 2323.55 \\
60 & 2362.77 \\
61 & 2402.36 \\
62 & 2442.01 \\
63 & 2481.44 \\
64 & 2520.99 \\
65 & 2560.31 \\
\hline
\end{tabular}




\begin{tabular}{|c|c|}
\hline 66 & 2600.03 \\
67 & 2639.44 \\
68 & 2679.02 \\
69 & 2718.21 \\
70 & 2760.84 \\
71 & 2798.7 \\
72 & 2838.08 \\
73 & 2877 \\
74 & 2916.27 \\
75 & 2955.72 \\
76 & 2995.29 \\
77 & 3035.09 \\
78 & 3073.89 \\
79 & 311.26 \\
80 & 3151.67 \\
81 & 3190.93 \\
82 & 3230.47 \\
83 & 3269.88 \\
84 & 3308.88 \\
85 & 3348.09 \\
86 & 3387.48 \\
87 & 3426.3 \\
88 & 3465.4 \\
89 & 3504.37 \\
90 & 3543.96 \\
91 & 3583.44 \\
92 & 3627.94 \\
93 & 3662.18 \\
94 & 3701.91 \\
95 & 3740.76 \\
96 & 3780.24 \\
97 & 3819.55 \\
98 & 3859.12 \\
99 & 3898.28 \\
100 & 3937.66 \\
101 & 3977.02 \\
102 & 4016.55 \\
103 & 4055.78 \\
104 & 4095.11 \\
105 & 4135.37 \\
106 & 4174.11 \\
107 & 4213.05 \\
108 & 4252.32 \\
109 & 4291.59 \\
110 & 4330.84 \\
111 & 4370.37 \\
112 & 4409.83 \\
113 & 4448.82 \\
114 & 4488.46 \\
115 & 4527.31 \\
116 & 4566.68 \\
117 & 4606.33 \\
118 & 4645.18 \\
119 & 4684.9 \\
120 & 4724.07 \\
121 & 4763.17 \\
\hline & \\
\hline
\end{tabular}

\begin{tabular}{|c|c|}
\hline 122 & 4802.71 \\
123.2 & 4849.32 \\
124 & 4881.75 \\
125 & 4920.33 \\
126 & 4959.51 \\
127 & 4998.78 \\
128 & 5037.55 \\
129 & 5076.87 \\
130 & 5116.81 \\
131 & 5155.2 \\
132 & 5194.99 \\
133 & 5233.96 \\
134 & 5273.05 \\
135 & 5312.1 \\
136 & 5351.32 \\
137 & 5390.4 \\
138 & 5429.58 \\
139 & 5468.29 \\
140 & 5507.48 \\
141 & 5546.49 \\
142 & 5585.56 \\
143 & 5624.56 \\
144 & 5663.49 \\
145 & 5702.28 \\
146 & 5741.58 \\
147 & 5787.19 \\
148 & 5819.06 \\
149 & 5857.93 \\
150 & 5896.73 \\
151 & 5935.36 \\
152 & 5974.48 \\
153 & 6013.18 \\
154 & 6051.58 \\
155 & 6089.89 \\
156 & 6128.24 \\
157 & 6167.52 \\
158 & 6205.43 \\
159 & 6243.37 \\
160 & 6282.15 \\
161 & 6320.21 \\
162 & 6358.22 \\
163 & 6397.01 \\
164 & 6434.19 \\
165 & 6473.12 \\
166 & 6509.27 \\
167 & 6546.85 \\
168 & 6584.13 \\
169 & 6621.23 \\
170 & 6658.4 \\
171 & 6695.52 \\
172 & 6732.08 \\
173 & 6768.77 \\
174 & 6805.38 \\
175 & 6842.49 \\
176 & 6877.53 \\
177 & 6913.28 \\
\hline & \\
\hline
\end{tabular}

\begin{tabular}{|c|c|}
\hline 178 & 6949.13 \\
179 & 6984.17 \\
180 & 7018.58 \\
181 & 7053.53 \\
182 & 7087.92 \\
183 & 7122.56 \\
184 & 7156.63 \\
185 & 7189.83 \\
186 & 7223.48 \\
187 & 7256.4 \\
188 & 7296.14 \\
189 & 7321.94 \\
190 & 7354.37 \\
191 & 7386.66 \\
192 & 7418.11 \\
193 & 7449.11 \\
194 & 7481.19 \\
195 & 7512.18 \\
196 & 7542.9 \\
197 & 7573.62 \\
198 & 7603.7 \\
199 & 7633.5 \\
200 & 7662.97 \\
201 & 7692.8 \\
202 & 7722.57 \\
203 & 7751.16 \\
204 & 7780.2 \\
205 & 7808.95 \\
206 & 7837.05 \\
207 & 7865.27 \\
208 & 7893.08 \\
209 & 7921.17 \\
210 & 7948.75 \\
211 & 7975.98 \\
212 & 8002.17 \\
213 & 8029.15 \\
214 & 8055.66 \\
215 & 8082.16 \\
216 & 8108.53 \\
217 & 8134.93 \\
218 & 8161 \\
219 & 8186.84 \\
220 & 8217.99 \\
221 & 8240.11 \\
222 & 8265.28 \\
223 & 8290.29 \\
224 & 8315.02 \\
225 & 8339.67 \\
226 & 8364.12 \\
227 & 8388.48 \\
228 & 8412.88 \\
229 & 8436.55 \\
230 & 8460.59 \\
231 & 8484.34 \\
232 & 8508.12 \\
233 & 8531.75 \\
\hline
\end{tabular}

\begin{tabular}{|c|c|}
\hline 234 & 8554.62 \\
235 & 8577.65 \\
236 & 8600.82 \\
237 & 8624.02 \\
238 & 8646 \\
239 & 8668.79 \\
240 & 8691.17 \\
241 & 8712.55 \\
242 & 8734.98 \\
243 & 8756.66 \\
244 & 8778.61 \\
245 & 8800.38 \\
246 & 8822.07 \\
247 & 8843.31 \\
248 & 8865.04 \\
249 & 8886.39 \\
250 & 8907.2 \\
251 & 8928.36 \\
252 & 8948.95 \\
253 & 8969.72 \\
254 & 8990.26 \\
255 & 9010.74 \\
256 & 9030.79 \\
257 & 9051.5 \\
258 & 9071.28 \\
259 & 9091.48 \\
260 & 911.09 \\
261 & 9131 \\
262 & 9151.09 \\
263 & 9169.47 \\
264 & 9188.88 \\
265 & 9209.54 \\
266 & 9228.46 \\
267 & 9247.74 \\
268 & 9267.06 \\
269 & 9285.73 \\
270 & 9304.64 \\
271 & 9323.61 \\
272 & 9342.01 \\
273 & 9360.4 \\
274 & 9379.09 \\
275 & 9397.45 \\
276 & 9415.92 \\
277 & 9433.86 \\
278 & 9452.15 \\
279 & 9470.14 \\
280 & 9487.97 \\
281 & 9505.9 \\
282 & 9523.28 \\
283 & 9540.99 \\
284 & 9558.72 \\
285 & 9576.09 \\
286 & 9593.25 \\
287 & 9610.32 \\
288 & 9627.47 \\
289 & 9644.13 \\
\hline & \\
\hline
\end{tabular}




\begin{tabular}{|c|c|}
\hline 290 & 9661.32 \\
291 & 9677.89 \\
292 & 9694.55 \\
293 & 9711.11 \\
294 & 9727.66 \\
295 & 9744.02 \\
296 & 9760.25 \\
297 & 9776.8 \\
298 & 9793.05 \\
299 & 9808.9 \\
300 & 9822.48 \\
301 & 9840.3 \\
302 & 9855.69 \\
303 & 9871.13 \\
304 & 9886.57 \\
305 & 9901.3 \\
306 & 9916.75 \\
307 & 9931.72 \\
308 & 9946.85 \\
309 & 9961.17 \\
310 & 9975.55 \\
311 & 9990.33 \\
312 & 10004.85 \\
313 & 10019.32 \\
314 & 10033.67 \\
315 & 10047.49 \\
316 & 10061.37 \\
317 & 10075.69 \\
318 & 10089.55 \\
319 & 10103.21 \\
320 & 10116.85 \\
321 & 10130.62 \\
322 & 10144.02 \\
323 & 10157.07 \\
324 & 10170.12 \\
325 & 10183.48 \\
326 & 10196.57 \\
327 & 10206.93 \\
328 & 10220.02 \\
329 & 10235.23 \\
330 & 10247.76 \\
331 & 10260.5 \\
332.7 & 10273.24 \\
333 & 10281.6 \\
334 & 10297.85 \\
335 & 10310.08 \\
336 & 10322.5 \\
337 & 10334.66 \\
\hline & \\
\hline
\end{tabular}

\begin{tabular}{|c|c|}
\hline 338 & 10346.67 \\
339 & 10358.7 \\
340 & 10371.06 \\
341 & 10382.77 \\
342 & 10394.37 \\
343 & 10405.82 \\
344 & 10417.56 \\
345 & 10429.04 \\
346 & 10440.42 \\
347 & 10453.75 \\
348 & 10465.19 \\
349 & 10476.22 \\
350 & 10487.54 \\
351 & 10498.37 \\
352 & 10509.59 \\
353 & 10520.89 \\
354 & 10531.25 \\
355 & 10542.17 \\
356 & 10553.56 \\
357 & 10564.34 \\
358 & 10575.2 \\
359 & 10585.55 \\
360 & 10596.81 \\
361 & 10607.69 \\
362 & 10618.2 \\
363 & 10628.56 \\
364 & 10636.28 \\
365 & 10649.67 \\
366 & 10660.11 \\
367 & 10670.66 \\
368 & 10681.24 \\
369 & 10691.74 \\
370 & 10702.01 \\
371 & 10712.44 \\
372 & 10722.97 \\
373 & 10733.09 \\
374 & 10743.69 \\
375 & 10753.57 \\
376 & 10763.83 \\
377 & 10773.85 \\
378 & 10784.12 \\
379 & 10793.88 \\
380 & 10804.36 \\
381 & 10814.16 \\
382 & 10824.38 \\
383 & 10834.3 \\
384 & 10844.19 \\
385 & 10854.27 \\
\hline
\end{tabular}

\begin{tabular}{|c|c|}
\hline 386 & 10864.11 \\
387 & 10873.99 \\
388 & 10883.61 \\
389 & 10893.83 \\
390 & 10903.38 \\
391 & 10913.3 \\
392 & 10923.66 \\
393 & 10933.17 \\
394 & 10943.23 \\
395 & 10952.76 \\
396 & 10962.63 \\
397 & 10972.17 \\
398 & 10982.05 \\
399 & 10991.55 \\
400 & 11001.08 \\
401 & 11031.44 \\
402 & 11020.85 \\
403 & 11030.21 \\
404 & 11039.63 \\
405 & 11049.14 \\
406 & 11058.42 \\
407 & 11068.1 \\
408 & 11077.58 \\
409 & 11087.1 \\
410 & 11096.36 \\
411 & 11105.62 \\
412 & 11115.25 \\
413 & 11124.68 \\
414 & 11133.77 \\
415 & 11142.97 \\
416 & 11152.27 \\
417 & 11161.59 \\
418 & 11170.68 \\
419 & 11179.34 \\
420 & 11189.04 \\
421 & 11198.12 \\
422 & 11207.01 \\
423 & 11216.22 \\
424 & 11225.08 \\
425 & 11234.13 \\
426 & 11242.9 \\
427 & 11252.2 \\
428 & 11260.86 \\
429 & 11269.68 \\
430 & 11278.7 \\
431 & 11287.36 \\
432 & 11295.99 \\
433 & 11305.15 \\
\hline & \\
\hline
\end{tabular}

\begin{tabular}{|l|l|}
\hline 434 & 11313.65 \\
435 & 11322.32 \\
\hline
\end{tabular}




\section{Magnetic field integrals}

The collection of first field integrals along the regular undulator periods is presented in Figure 48. The list of the first and the second integral values at the undulator output for the tuning settings is in Table 2. The second field integrals for all tuning settings are plotted below.

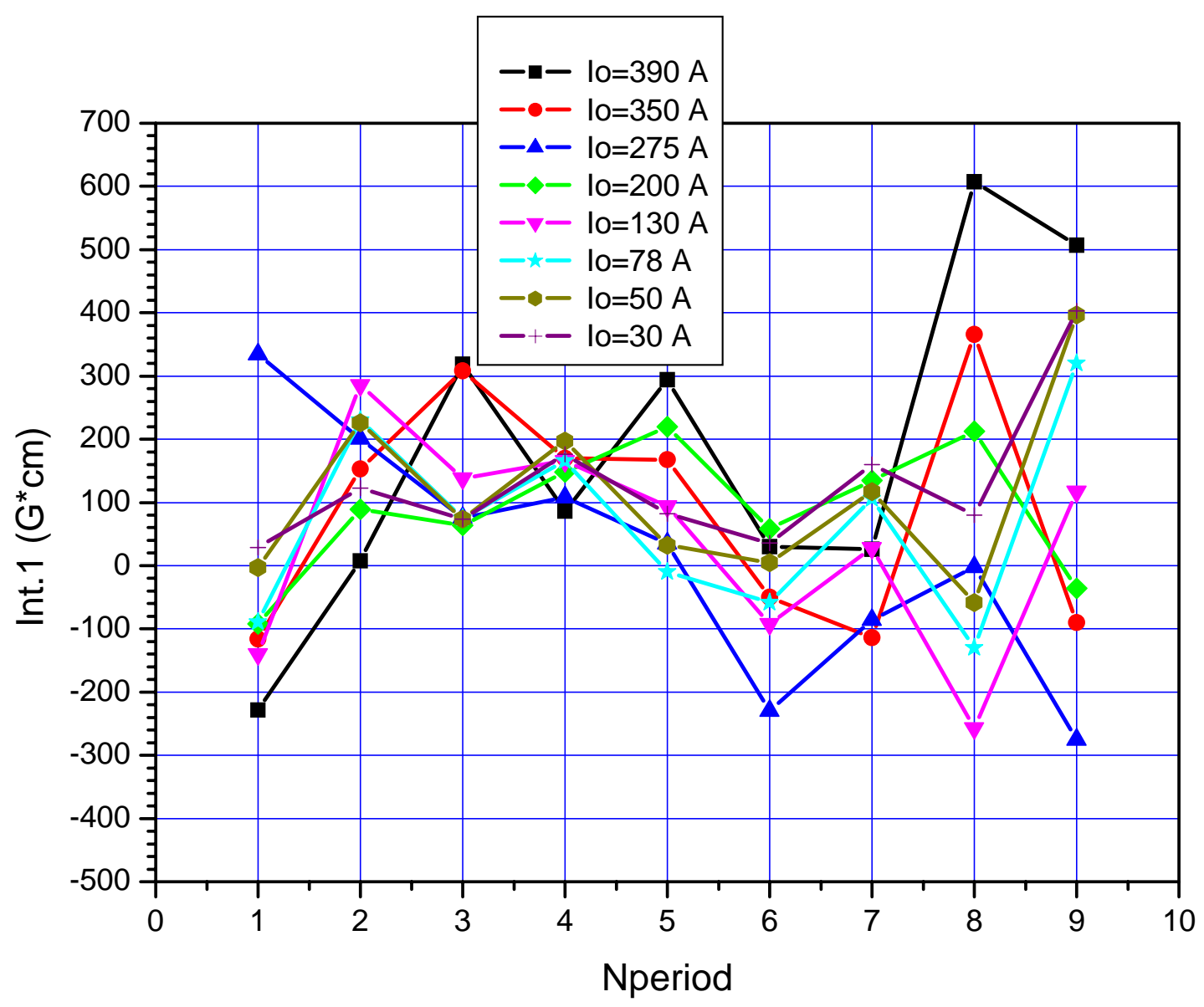

Figure 48 Magnetic field first integral for the undulator regular periods 

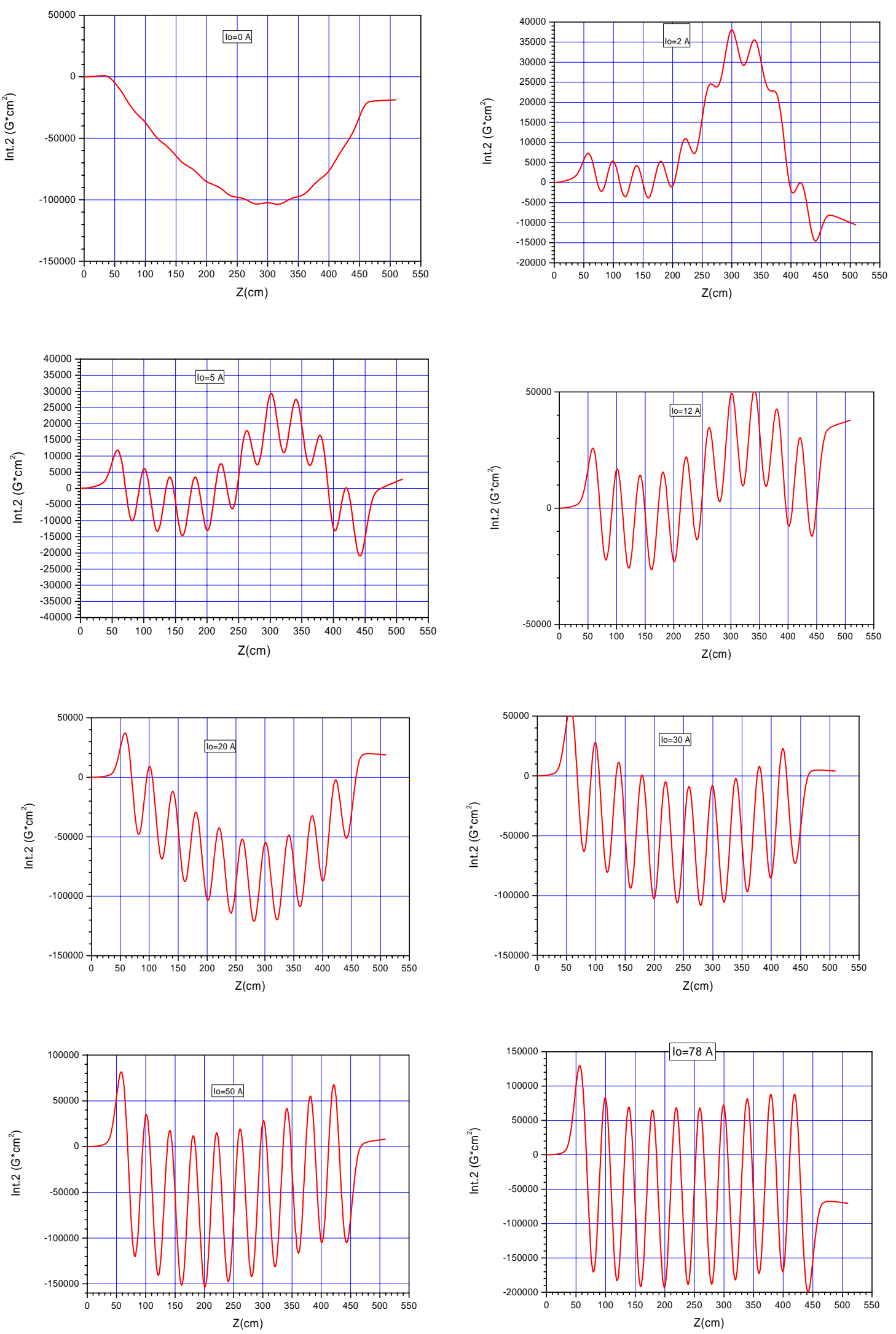

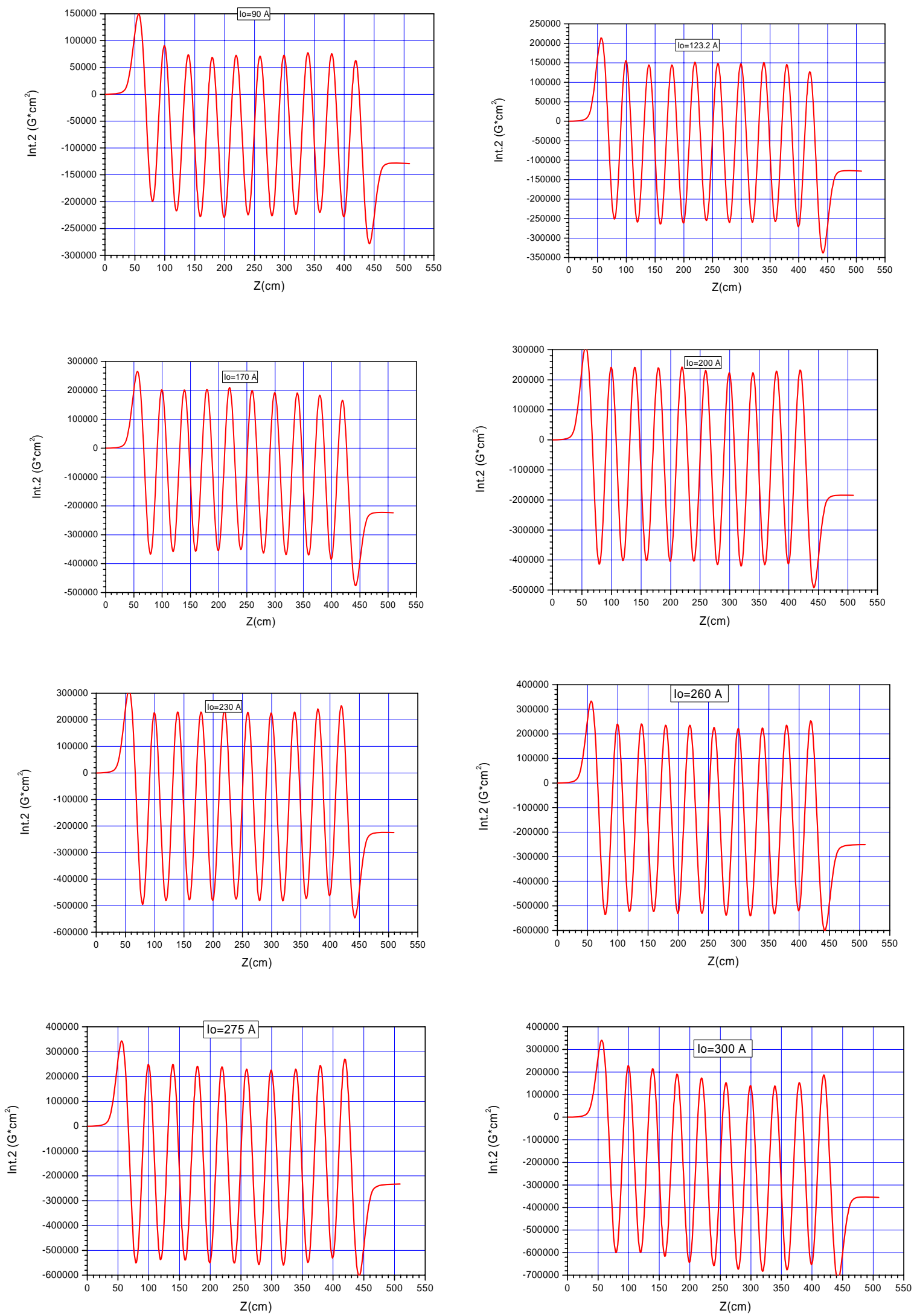

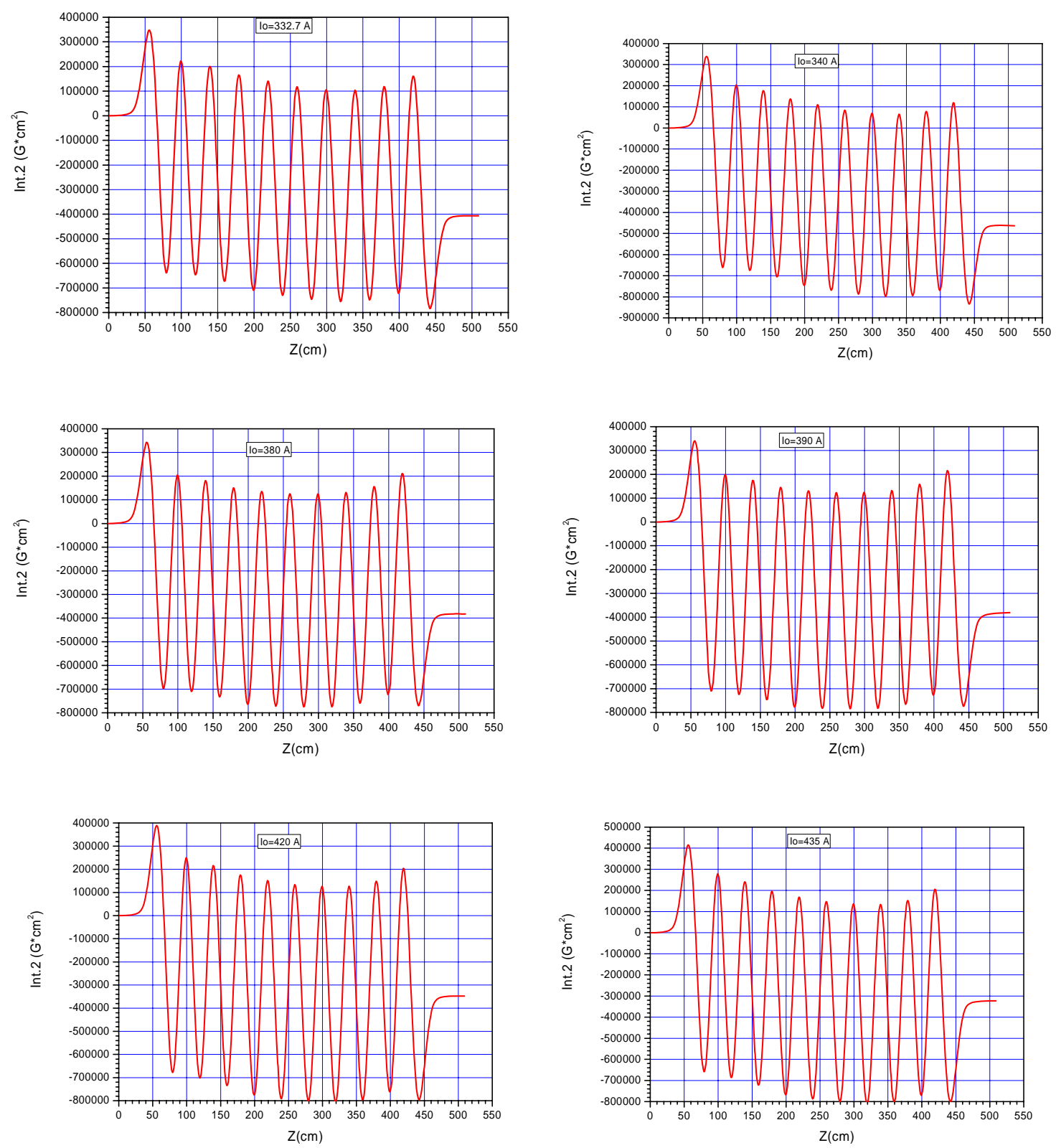

\section{Acknowledgments}

The help of Claus Jaekel, Peter Nommensen, Piotr Bartkiewicz and Vitali Kocharyan in setting up the control system for operation of the undulator in the measurement hall at DESY is acknowledged with pleasure. Markus Tischer provided valuable advice in defining the measurement program. Mikhail Yurkov kindly provided helpful comments and guidance all along the infrared undulator project. 